\title{
Tetracyclines promote survival and fitness in mitochondrial disease models
}

\author{
Elizabeth A. Perry 1,2,3,5, Christopher F. Bennett ${ }^{1,2,5}$, Chi Luo ${ }^{1,2}$, Eduardo Balsa, ${ }^{1,2}$, Mark Jedrychowski ${ }^{1,2}$, \\ Katherine E. O'Malley,1,2, Pedro Latorre-Muro ${ }^{1,2}$, Richard Porter Ladley ${ }^{4}$, Kamar Reda4, \\ Peter M. Wright ${ }^{4}$, Steven P. Gygi ${ }^{2}{ }^{2}$, Andrew G. Myers ${ }^{4}$ and Pere Puigserver $\mathbb{C}^{1,2}{ }^{\square}$
}

\begin{abstract}
Mitochondrial diseases (MDs) are a heterogeneous group of disorders resulting from mutations in nuclear or mitochondrial DNA genes encoding mitochondrial proteins ${ }^{1,2}$. MDs cause pathologies with severe tissue damage and ultimately death ${ }^{3,4}$. There are no cures for MDs and current treatments are only palliative $^{5-7}$. Here we show that tetracyclines improve fitness of cultured MD cells and ameliorate disease in a mouse model of Leigh syndrome. To identify small molecules that prevent cellular damage and death under nutrient stress conditions, we conduct a chemical high-throughput screen with cells carrying human MD mutations and discover a series of antibiotics that maintain survival of various MD cells. We subsequently show that a sub-library of tetracycline analogues, including doxycycline, rescues cell death and inflammatory signatures in mutant cells through partial and selective inhibition of mitochondrial translation, resulting in an ATF4-independent mitohormetic response. Doxycycline treatment strongly promotes fitness and survival of $\mathrm{Ndufs}^{-/-}$mice, a preclinical Leigh syndrome mouse model ${ }^{8}$. A proteomic analysis of brain tissue reveals that doxycycline treatment largely prevents neuronal death and the accumulation of neuroimmune and inflammatory proteins in Ndufs $4^{-/-}$mice, indicating a potential causal role for these proteins in the brain pathology. Our findings suggest that tetracyclines deserve further evaluation as potential drugs for the treatment of MDs.
\end{abstract}

MDs cause diverse pathologies including neurodegeneration, cardiac and muscle myopathies, liver and kidney failures, deafness and ultimately death ${ }^{3,9}$. Since there are currently no effective therapies for MDs, we aimed to identify small molecules that ameliorate the detrimental phenotypes and death associated with mitochondrial mutations. As a cellular model for MDs, we used human MELAS homoplasmic mutant cybrid cells (A3243G $\left.t R N A^{\text {Leu(UUR) }}\right)^{10}$ that exhibit complete reduction in respiratory complex function (Extended Data Fig. 1a) and rely heavily on glycolysis for survival and proliferation ${ }^{11}$. These mutant cells die in glucose restriction conditions from apoptosis (Extended Data Fig. 1b), a phenotype that can be exploited for screening read-outs (Fig. 1a). We designed a high-throughput chemical screen platform using MELAS cybrid cells scoring viability after $48 \mathrm{~h}$ in low-glucose culture medium (2.5 mM; Fig. 1a). From a library of 4,937 known bioactive compounds screened, we identified 184 hits $(z$-score $>1.96,97.5 \%$ confidence interval) that promoted cell survival (Fig. 1b). The main classes of compounds included tetracycline antibiotics, p53 activators, and drugs that inhibit HSP90 and the mammalian target of rapamycin (mTOR; Fig. 1c). mTOR inhibitors improve lifespan in multiple models of $\mathrm{MDs}^{12-15}$, validating our screening platform for moving compounds towards in vivo testing. Top hits from the screen were retested in a non-high-throughput 7-d low-glucose cell survival assay (Fig. 1d). Among the top-scoring compounds, tetracyclines such as doxycycline promoted the highest survival and proliferation in MELAS cells (Fig. 1d). These effects were not exclusive to MELAS cybrids as other mitochondrial mutant cells such as Rieske (complex III) knockout (KO) mouse fibroblasts ${ }^{16}$ and ND1 A3796G and ND6 G14459A (complex I) ${ }^{17}$ homoplasmic mutant cybrid cells were rescued from cell death by doxycycline treatment in glucose restriction conditions (Fig. 1e-i). Notably, the pro-survival effects of doxycycline were independent of shifts in mutant mitochondrial DNA (mtDNA) levels (Extended Data Fig. 1c) in cybrids or respiratory chain complex levels (Extended Data Fig. 1d-f). Doxycycline also improved survival in wild-type cells treated with piericidin (complex I inhibitor) or antimycin (complex III inhibitor) during glucose deprivation (Fig. 1j). These results indicate that tetracycline antibiotics promote cell survival under nutrient stress in different cellular models of MDs.

In addition to tetracyclines, the anti-parasitic agent pentamidine and the antibiotic retapamulin also scored positive on the screen and were retested at the same dose in MELAS and ND1 cybrid cells (Fig. 1k-r). These data suggested that mitochondrial translation might be a relevant target: while doxycycline and pentamidine are known to inhibit eukaryotic mitochondrial translation ${ }^{18-20}$, retapamulin inhibits prokaryotic translation and could potentially inhibit mitochondrial translation ${ }^{21}$. To examine this, we measured rates of mitochondrial translation with $\left[{ }^{35} \mathrm{~S}\right]$ methionine and $\left[{ }^{35} \mathrm{~S}\right]$ cysteine labelling using different concentrations of these antibiotics. Consistent with cell survival effects between $100 \mathrm{nM}$ and $1 \mu \mathrm{M}$ (Fig. 1k-r and Extended Data Fig. 2a), antibiotics did not reduce mitochondrial translation at $10 \mathrm{nM}$, partially reduced it between $100 \mathrm{nM}$ and $1 \mu \mathrm{M}$, and strongly suppressed it above $10 \mu \mathrm{M}$ in ND1 cybrid cells (Figs. 1k-r and $2 \mathrm{a}-\mathrm{c}$ ). This sensitivity also occurred in MELAS cybrid cells, despite the mitochondrial $t R N A^{L e u}$ mutation (Extended Data Fig. 2b). Thus, cell survival from antibiotics followed a mitohormetic distribution ${ }^{22}$ (Figs. 1n,r and 2c), suggesting that partial or attenuated mitochondrial translation caused by these antibiotics promotes a protective cellular response.

To investigate structure-activity relationships (SARs) within the tetracycline scaffold, we used chemical synthesis to introduce

'Department of Cancer Biology, Dana-Farber Cancer Institute, Boston, MA, USA. ²Department of Cell Biology, Harvard Medical School, Boston, MA, USA. ${ }^{3}$ Biological Sciences in Dental Medicine Program, Harvard School of Dental Medicine, Boston, MA, USA. ${ }^{4}$ Department of Chemistry and Chemical Biology, Harvard University, Cambridge, MA, USA. ${ }^{5}$ These authors contributed equally: Elizabeth A. Perry, Christopher F. Bennett.

凶e-mail: pere_puigserver@dfci.harvard.edu 
structural diversity at positions C5, C5a, C6, C7 and C9, generating a library of 45 fully synthetic tetracycline analogues including substituted sancyclines, minocyclines, doxycyclines and pentacyclines, as well as the semi-synthetic analogue known as CMT-3 (refs. ${ }^{23-26}$ ). The compounds were screened in cell survival and mitochondrial protein synthesis assays. Figure $2 \mathrm{e}$, f shows that a number of the new tetracycline analogues both promoted cell survival in ND1 cybrids when cultured under conditions of nutrient stress and inhibited mitochondrial translation. Tetracycline analogues that most strongly rescued cell death in ND1 cybrids include various C5- or C5a-substituted minocycline analogues (for example, 7026, 7038 and 7066), pentacyclines (for example, 7002 and 7003) and certain C6-aryl-substituted tetracyclines (for example, 7007, 7014, 7015 and 7019), but not all (for example, 7004, 7013 and 7018; Fig. 2e,f and Supplementary Table 1). Among the C6-aryl analogues, those that did not promote cell survival also did not inhibit mitochondrial translation, whereas all those that rescued cells did inhibit mitochondrial translation to varying levels (Fig. 2e,f). These data suggest that mitochondrial translation attenuation is beneficial to the survival of ND1 mutant cells. Although small, the dataset makes clear that the SAR for cell rescue within the tetracycline class is far from narrow, but suggests instead that there is broad opportunity for further molecular optimization.

To clarify the dependence on mitochondrial translation inhibition for cell survival, we targeted components of the mitochondrial translation machinery. First, we treated ND1 cybrid cells with ethidium bromide (EtBr) to deplete mtDNA and thus mitochondrial-encoded rRNA ${ }^{27}$. Doxycycline did not rescue ND1 cybrid cells without mtDNA (Fig. 2g). Furthermore, ND1 mutant CRISPR KO cells depleted of MRPL4, a mitochondrial ribosome subunit, or GFM2, a mitochondrial translation factor, were not rescued under nutrient stress conditions with doxycycline treatment (Fig. 2h and Extended Data Fig. 2c,d). Mitochondrial translation inhibition initiates an integrated stress response mediated by ATF4 (ref. ${ }^{28}$ ). We confirmed that MELAS cells treated with doxycycline induced ATF4 and p-eIF2 $\alpha$ levels (Extended Data Fig. 3a); however, cell survival was independent of ATF4 (Extended Data Fig. $3 b-d)$. Previous studies implicate different protein targets for doxycycline including poly(ADP-ribose) polymerase-1 (ref. ${ }^{29}$ ), protease-activated receptor-1 (ref. ${ }^{30}$ ) and matrix metalloproteinases $^{31}$. Consistent with the requirement of mitochondrial translation attenuation, inhibitors and/or genetic deletion of these factors were not sufficient to promote survival in MELAS or ND1 cells (Extended Data Fig. 3e-1).

MD mutant cells activate inflammatory responses, particularly under nutrient stress conditions ${ }^{32-36}$ (Extended Data Fig. 4a). Doxycycline and tetracycline analogues suppressed inflammatory gene expression in MELAS or ND1 cybrid cells (Extended Data
Fig. $4 \mathrm{~b}, \mathrm{c})$ in a manner that correlated with mitochondrial translation inhibition. To further explore this relationship and its connection to metabolism, we determined the metabolic response of ND1 cells treated with analogues with (7066 and doxycycline) or without (7004, 7013 and CMT-3) effects on mitochondrial translation and cell survival (Supplementary Table 2). There were 15 metabolites that differentiated these groups $(P<0.05$, Student's $t$-test with Bonferroni correction) in processes such as glycolysis, pentose phosphate pathway and nucleotide synthesis (Extended Data Fig. 5a). A subset of these metabolites $(10 / 15)$ increased in ND1 cells propagated in galactose medium from 24 to $72 \mathrm{~h}$ and correlated with inflammatory gene expression (Extended Data Fig. 5b,c and Supplementary Table 3). NADPH redox changes were apparent at $24 \mathrm{~h}$ with doxycycline (Extended Data Fig. 5c), suggesting normalization of cellular redox may be the initial anti-inflammatory pro-survival event consistent with our previous finding $\mathrm{s}^{37}$. Interestingly, suppression of inflammation with the p38 inhibitor SB203580 replicated aspects of the doxycycline metabolic signature (Extended Data Fig. 6a,b and Supplementary Table 4). The $\mathrm{NADP}^{+} / \mathrm{NADPH}$ ratio decreased with SB203580 and decreased further with doxycycline (Extended Data Fig. $6 c, d$ ), arguing a fraction of doxycycline effects on redox occurs independently of inflammatory signalling. Together, these data support a model where partial or attenuated mitochondrial translation inhibition normalizes cellular redox, reduces inflammatory gene expression and increases survival in MD mutant cells (Fig. 2i).

Given the ability of tetracyclines to rescue several in vitro models of MDs, we investigated whether doxycycline shows efficacy in a mouse model of a human MDs. Mice lacking the mitochondrial complex I protein NDUFS4 closely recapitulate Leigh syndrome, the most common paediatric manifestation of $\mathrm{MDs}^{38}$. These mice are generally healthy until around postnatal day 35 (P35), at which point they begin to lose weight and become ataxic and lethargic. Without treatment, the mice meet the criteria for humane euthanasia at $\sim$ P58. Following weaning at $\sim \mathrm{P} 21, N d u f_{s} 4^{-/-}(\mathrm{KO})$ mice along with their wild-type and heterozygous littermate controls (referred to collectively as 'WT') were randomly assigned to 5,000 p.p.m. doxycycline, 8,000 p.p.m. doxycycline or control diet groups. With either diet, there was accumulation of doxycycline in brain and liver of wild-type and $\mathrm{KO}$ animals at concentrations consistent with other feeding studies ${ }^{39}$ (Extended Data Fig. 7a,b). Doxycycline ameliorated the decline in body weight that occurred in KO mice around P35 (Fig. 3a). Doxycycline-treated KO mice lived significantly longer than untreated controls $(P<0.0001$ for both treatment groups). Median survival was 100 and $107 \mathrm{~d}$ for the 5,000 p.p.m. and 8,000 p.p.m. groups respectively, with a maximum lifespan of $341 \mathrm{~d}$ (Fig. 3b). KO mice exhibit a progressive neurological decline that leads to decreased motor function and activity ${ }^{8}$. A rotarod test was used at P30, P40 and P50 to assess motor function

Fig. 1 Small-molecule screen identifies antibiotics as suppressors of cell death in cellular models of human mitochondrial disease. a, Schematic of the high-throughput small-molecule screen to identify compounds that increase survival of MELAS cybrid cells. b, Plot of $z$-scores for each compound from two replicates (rep. 1 and rep. 2). Antibiotics targeting the mitochondrial ribosome are highlighted in blue (Pearson correlation: $\left.R^{2}=0.5704 ; P<0.0001\right)$. , Plot of average $z$-scores $\left(z\right.$-score ${ }_{A V G}$ ) for a particular protein against the number of compounds for that target. For compounds with multiple annotated target proteins, the compound $z$-score was incorporated into each protein target $z$-score ${ }_{\text {AvG }}$. d, Results for the 7-d low-glucose survival assay of MELAS cybrid cells treated with $3.3 \mu \mathrm{M}$ compound ( $n=2$ biologically independent samples). e, Comparison of electron-transfer chain defects between the different cell lines used in the studies. MELAS, ND1 and ND6 (LHON) are human cybrid cell lines and Rieske is a mouse fibroblast cell line. Figure reproduced from ref. ${ }^{8}$. Reprinted with permission from AAAS. f,g, Results for the 7-d low-glucose survival assay of MELAS cybrid or Rieske cells treated with doxycycline (MELAS, $n=2-3$; Rieske, $n=2$ biologically independent samples). h, Results for the 14-d galactose survival assay of ND1 cybrid cells treated with doxycycline ( $n=3$ biologically independent samples). $\mathbf{i}$, Results for the 7-d galactose survival of LHON cybrid cells treated with doxycycline ( $n=3$ biologically independent samples). j, Cell survival of U2OS control cells treated with $1 \mathrm{nM}$ piericidin or $5 \mathrm{nM}$ antimycin with $1 \mu \mathrm{M}$ doxycycline in galactose medium ( $n=2-3$ biologically independent samples over $n=2$ independent experiments). $\mathbf{k}-\mathbf{m}$, Results for the 48-h low-glucose survival assay of MELAS cybrid cells ( $n=2$ biologically independent samples over $n=2$ independent experiments). $\mathbf{n}$, Overlay of $\mathbf{k}-\mathbf{m}$. $\mathbf{0}-\mathbf{q}$, Results for the 7-d galactose survival assay of ND1 cybrid cells titrated with three structurally distinct antibiotics (doxycycline, $n=2$; pentamidine, $n=2$; retapamulin, $n=4$ biologically independent samples). $\mathbf{r}$, Overlay of $\mathbf{0}-\mathbf{q}$. Survival assays were initially seeded with $1.0 \times 10^{5}$ cells with medium changed every $24 \mathrm{~h}$ for low-glucose assays and $48 \mathrm{~h}$ for galactose assays. Data are presented as the mean \pm s.e.m.; Student's $t$-test with a two-stage linear step-up procedure of Benjamini, Krieger and Yekutieli, with $Q=5 \%$, ${ }^{\star} q<0.05$. 
in doxycycline-treated KO and WT mice. Doxycycline significantly improved rotarod performance in $\mathrm{KO}$ mice at P40 and P50 without affecting WT performance (Fig. $3 \mathrm{c}-\mathrm{e}$ ). These results indicate that doxycycline treatment increases survival and fitness in a preclinical mouse model of MD.

Given the profound phenotypic improvement of the doxycycline-treated mice, we tested whether doxycycline may correct the underlying neuropathology observed in the $\mathrm{Ndufs4^{-/ }}$ mouse model. KO mice developed bilateral lesions in the vestibular nuclei and the olfactory bulb. These lesions were marked by microglial activation evidenced by elevated $I b a-1$ expression
(Fig. 4a). Immunohistochemistry analysis showed that Iba-1 levels were significantly lower in the vestibular nucleus and olfactory bulb in the doxycycline-treated $\mathrm{KO}$ mice compared to levels in untreated $\mathrm{KO}$ mice $(q<0.05$; Fig. $4 \mathrm{a}, \mathrm{b})$. To identify how doxycycline prevents this neuropathology in $\mathrm{KO}$ mice, we performed isobaric quantitative-based mass spectrometry analysis ${ }^{40}$ using whole-brain tissues from WT, $\mathrm{KO}$ and doxycycline-treated $\mathrm{KO}$ mice at P55 (Supplementary Table 5). As predicted, mitochondrial complex I proteins were robustly decreased in $\mathrm{KO}$ mice compared to WT controls and were not rescued by doxycycline (Extended Data Fig. 7c). Gene ontology analysis identified 'immune process' and a

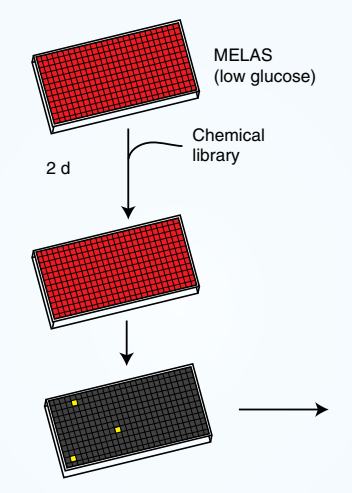

ATP bioluminescence

Data acquisition

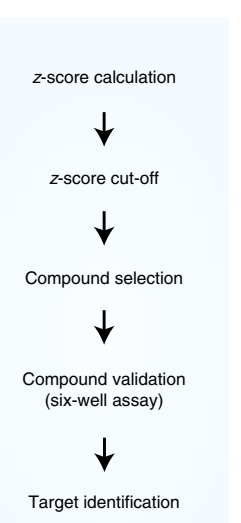

Data analysis
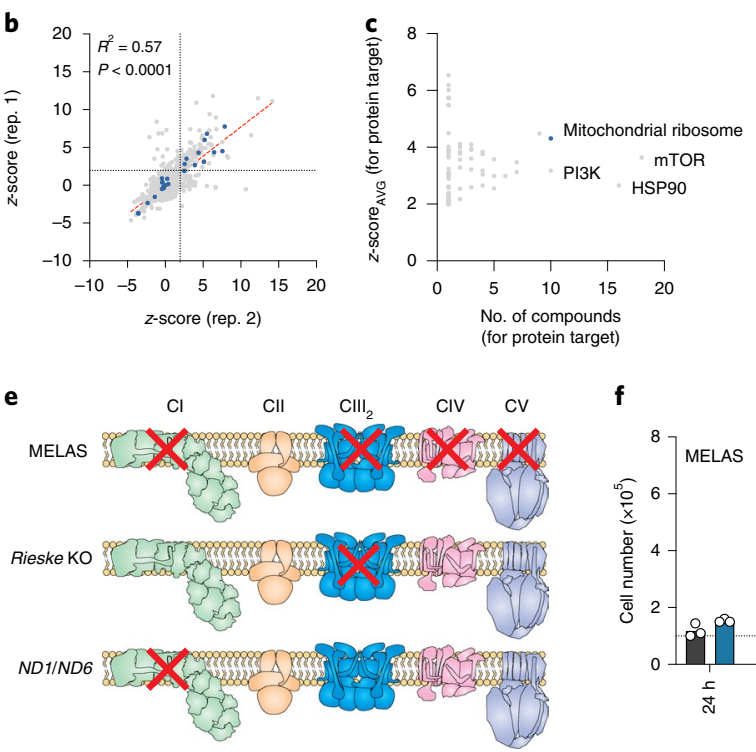

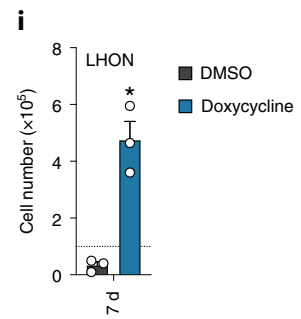

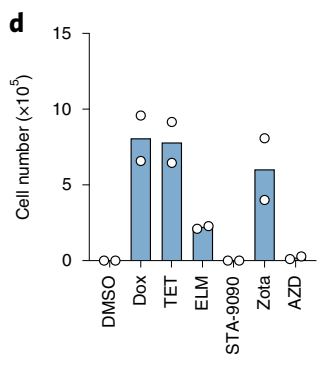

f

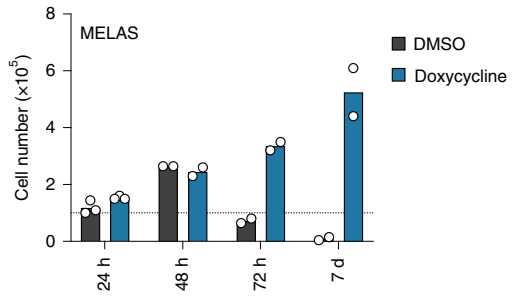

g

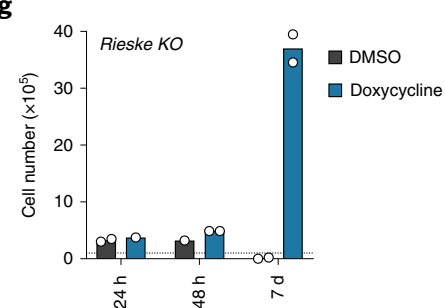

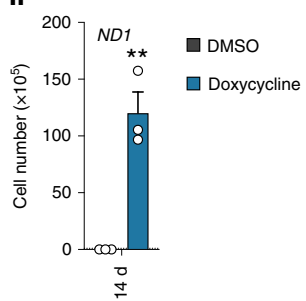

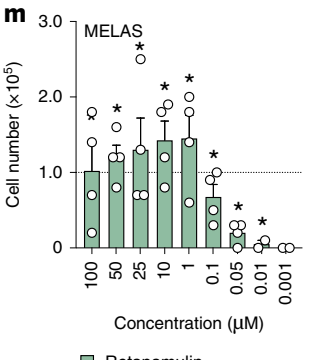

$\square$ Retapamulin

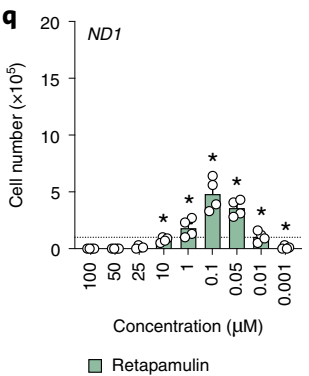

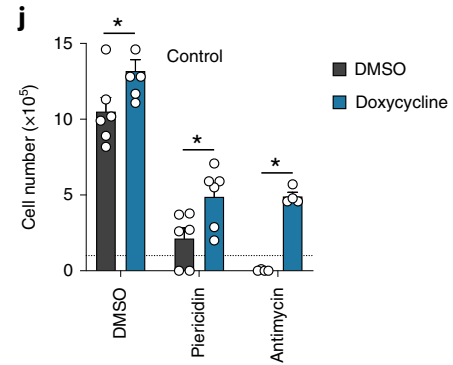

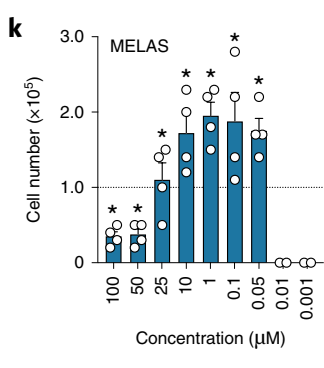

$\square$ Doxycycline

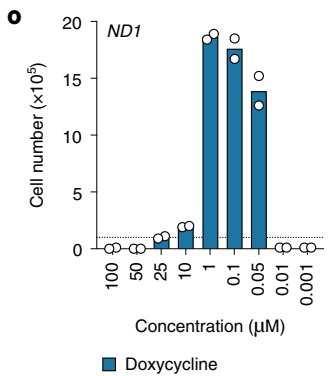

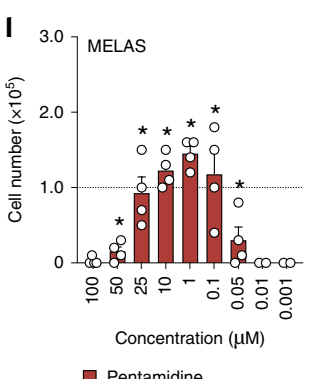

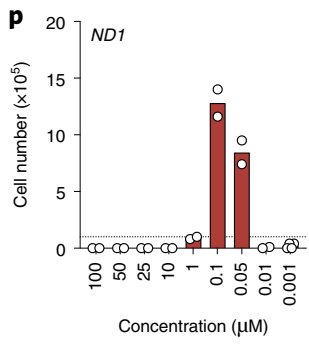

Pentamidine
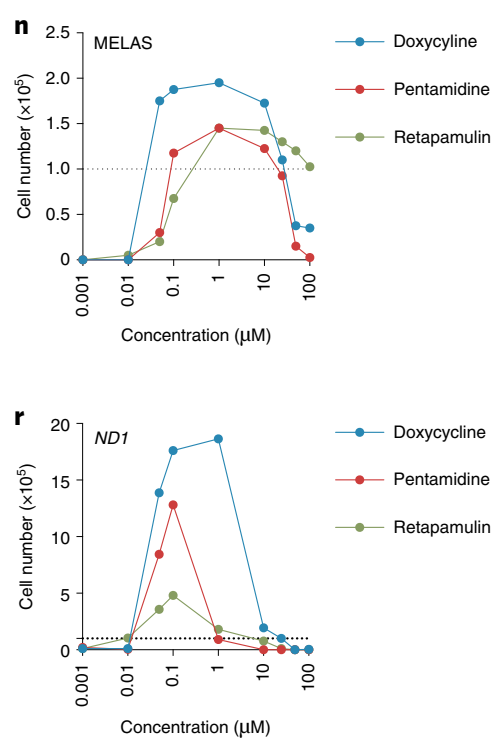


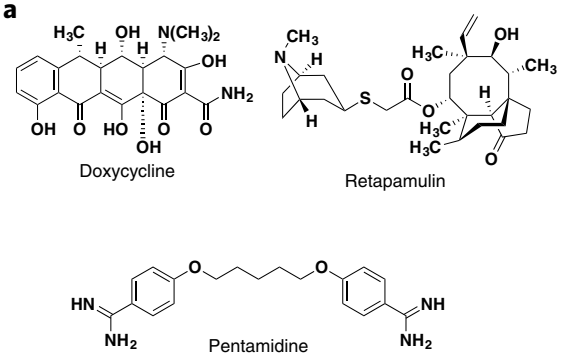

b

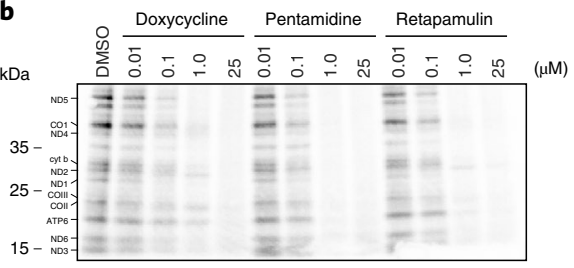

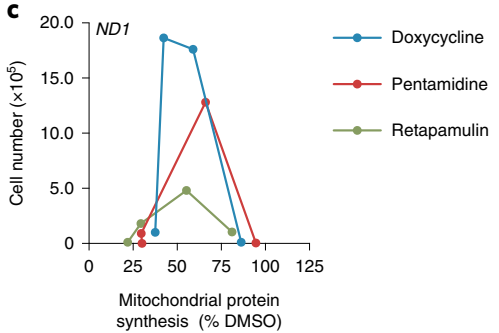

d
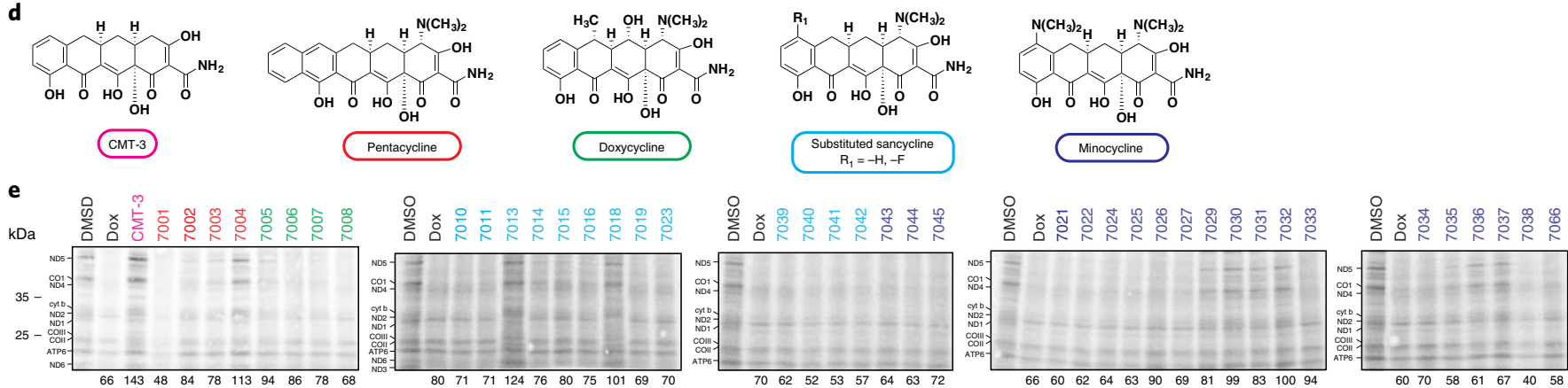

f
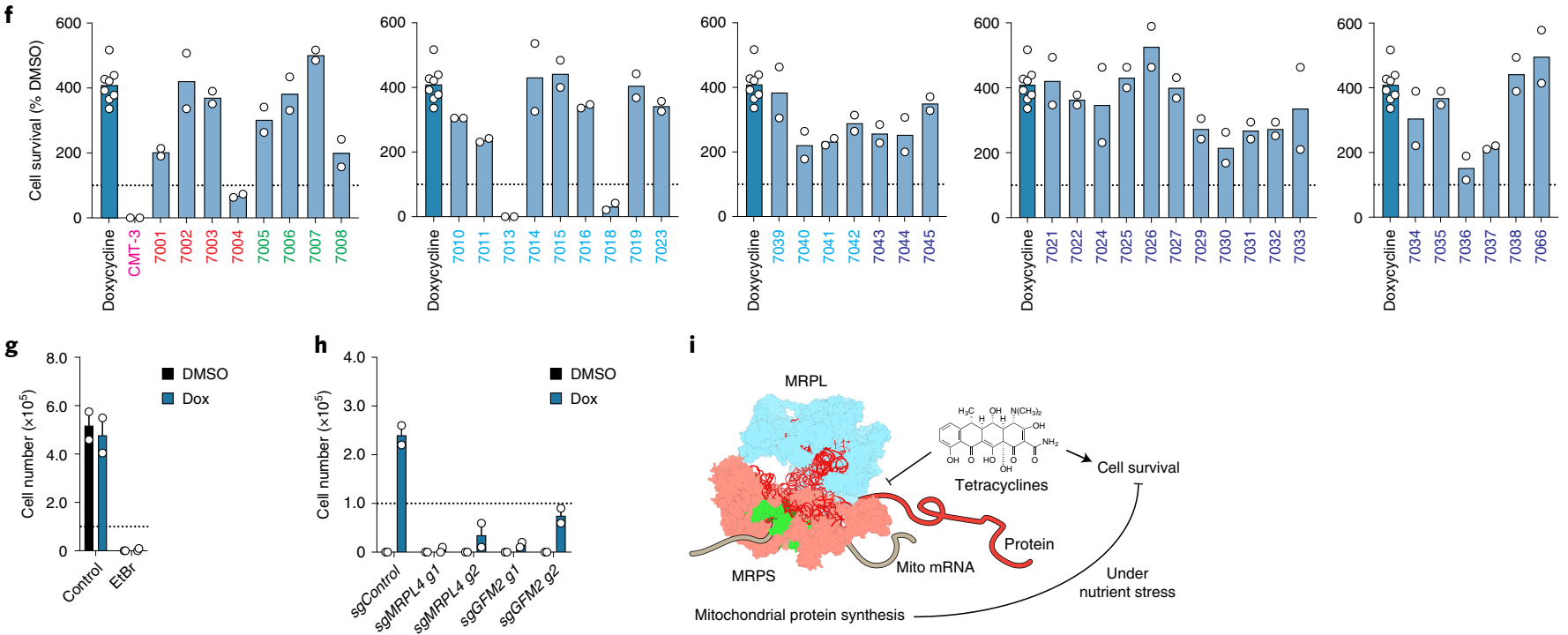

i

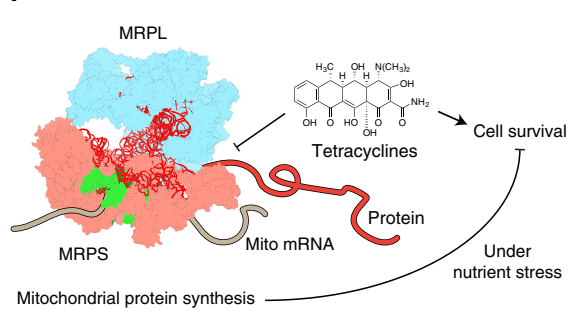

Fig. 2 | Antibiotic-mediated mitochondrial translation attenuation is required to promote cell survival in human mitochondrial disease mutant cells. a, Chemical structures of doxycycline, retapamulin and pentamidine. $\mathbf{b},{ }^{35} \mathrm{~S}$-labelled cysteine and methionine pulse in ND1 cybrid cells treated with doxycycline, pentamidine or retapamulin at $10 \mathrm{nM}, 100 \mathrm{nM}, 1 \mu \mathrm{M}$ or $25 \mu \mathrm{M}$ with a 48 -h pretreatment and 1-h pulse ( $n=2$ experiments). c, Mitochondrial protein synthesis and cell survival in ND1 cybrid cells (data from Fig. 10-q and quantification of b). d, Parent chemical structures for tetracycline analogues used in the screen. $\mathbf{e}^{35} \mathrm{~S}$-labelled cysteine and methionine pulse in ND1 cybrid cells pretreated with $1 \mu \mathrm{M}$ tetracycline compounds for $48 \mathrm{~h}$ in glucose conditions before the 1-h pulse in the presence of compound ( $n=2$ experiments). $\mathbf{f}$, Results for the 4-d galactose survival assay of ND1 cybrid cells treated with $1 \mu \mathrm{M}$ tetracycline analogues ( $n=2$ biologically independent samples). $\mathbf{g}$, Results for the 48-h galactose survival assay of ND1 cybrid cells propagated in EtBr ( $50 \mathrm{ng} \mathrm{ml}^{-1}$ for 3 weeks) and treated with doxycycline (dox; $n=2$ biologically independent samples). $\mathbf{h}$, Results for the 48 - $h$ galactose survival assay of sgControl, sgMRPL4 and sgGFM2 ND1 cybrid cells treated with doxycycline ( $n=2$ biologically independent samples). i, Tetracyclines antibiotics attenuated mitochondrial translation and promoted cell survival of MD mutant cells under nutrient stress conditions. Ribosome model adapted from the Protein Data Bank (PDB: 5AJ4; ref. ${ }^{69}$ ). MRPL: mitochondrial ribosome protein, large; MRPS: mitochondrial ribosome protein, small. Survival assays were initially seeded with $1.0 \times 10^{5}$ cells with medium changed every $48 \mathrm{~h}$. Data are presented as the mean \pm s.e.m.; Student's $t$-test with a two-stage linear step-up procedure of Benjamini, Krieger and Yekutieli, with $Q=5 \%$, * $q<0.05$.

'innate immune system' as the most significantly altered pathways by doxycycline treatment (Fig. 4c). Proteins associated with neuroimmune and inflammation, including markers of microglial and astrocyte activation (LEG3, CD180, GFAP and S100A4), complement components (C1QA and $\mathrm{C} 1 \mathrm{QB})$ and the interferon response (IFIT1 and IFIT3) ${ }^{41-43}$, were significantly upregulated in KO mice compared to WT, and largely suppressed by doxycycline (Fig. 4d-f).
Doxycycline treatment also upregulated proteins associated with anti-inflammatory responses (CLINT1, OTUD4 and APOA4) ${ }^{44-46}$ (Supplementary Table 5). To further investigate these protective effects of doxycycline, we performed targeted metabolomics using brains of P55 WT and KO mice and compared them to ND1 cybrid cells under galactose conditions with and without doxycycline treatment (Supplementary Tables 6 and 7). Doxycycline changed a subset 

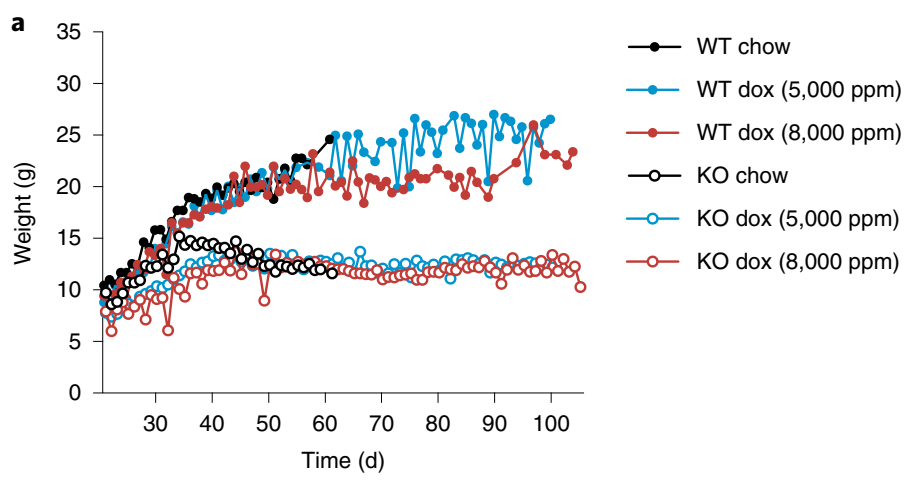
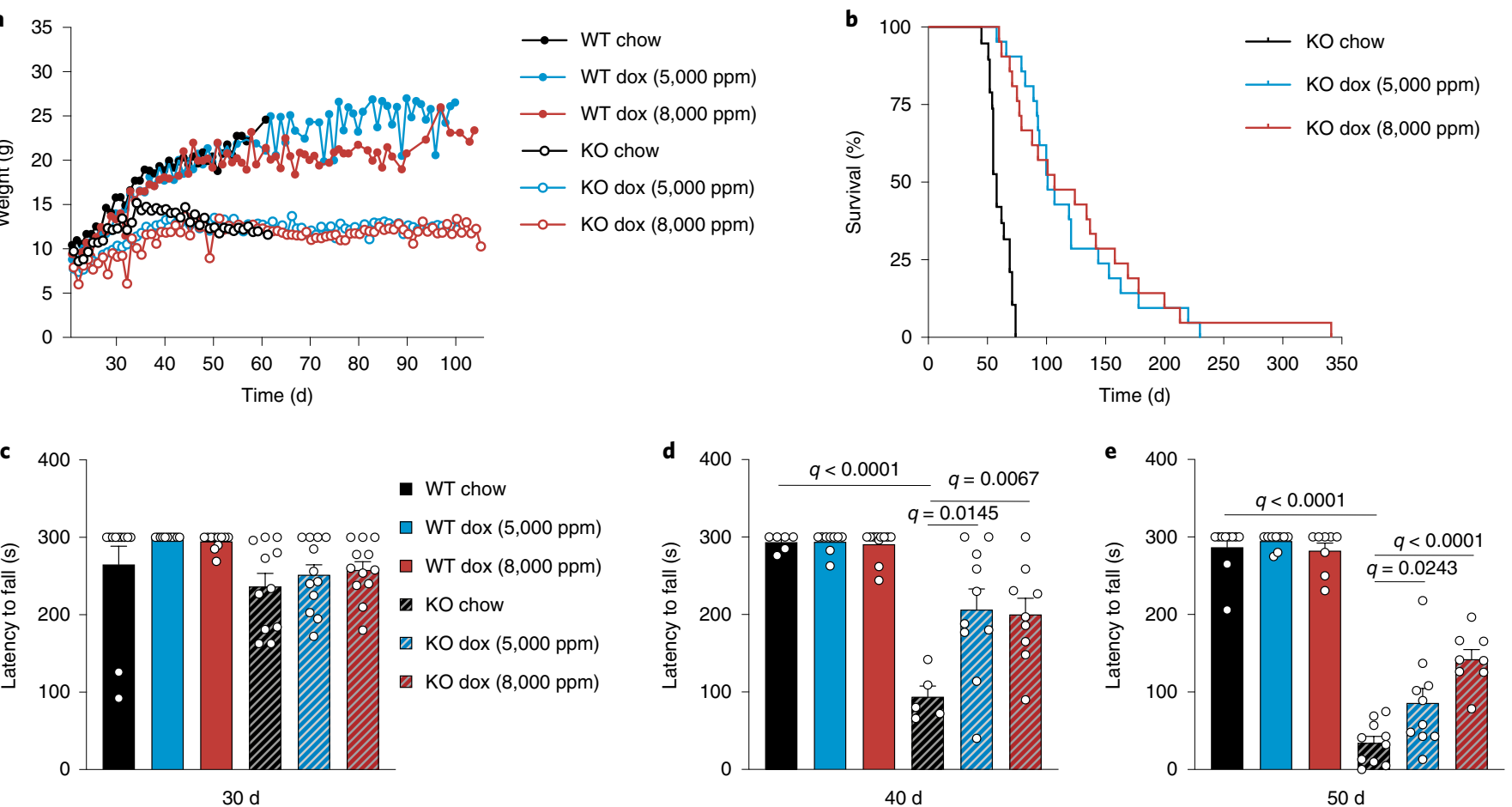

Fig. 3 | Doxycycline significantly increases the lifespan and fitness of a mouse model of complex I deficiency. a, Body weight of Ndufs4-/- KO and WT mice over time ( $n=10$ WT and KO chow; $n=8$ WT and KO doxycycline 5,000 p.p.m.; $n=10$ KO doxycycline 8,000 p.p.m.; and $n=7$ WT doxycycline 8,000 p.p.m. mice). b. Survival of Ndufs $4^{-/-}$mice was significantly increased with dietary doxycycline supplementation at 5,000 p.p.m. and 8,000 p.p.m. ( $n=19$ chow; $n=21$ dox 5,000 p.p.m.; and $n=21$ dox 8,000 p.p.m. mice; $P<0.0001$, log-rank test for both treatments compared to chow control). c-e, Rotarod performance of KO and WT mice at 30, 40 and $50 \mathrm{~d}$. Untreated KO mice showed a progressive decline in performance, which was partially prevented with doxycycline treatment. Maximum time of $300 \mathrm{~s}$ with three attempts per mouse for each time point. The maximum time is represented (at least $n=5$ mice were tested per treatment at each time point). Data are presented as the mean \pm s.e.m.; Student's $t$-test with a two-stage linear step-up procedure of Benjamini, Krieger and Yekutieli, with $Q=5 \%,{ }^{\star} q<0.05$.

of metabolites that were altered in KO mice and ND1 cybrid cells (Extended Data Fig. 7d,e) and increased metabolomic signatures associated with attenuation of immune, inflammatory and oxidative stress responses such as NADPH/glutathione redox, polyamine biosynthesis and itaconic acid ${ }^{4-50}$ (Fig. $4 \mathrm{~g}-\mathrm{i}$ and Extended Data Fig. 7e-g). Since oxidative stress is considered the main pathological cause of MDs, these metabolic changes are consistent with suppression of the disease phenotype $\mathrm{e}^{47-49,51-53}$. Doxycycline also increased glutamine and glutamate levels in Ndufs $4 \mathrm{KO}$ mice and ND1 cybrid cells (Fig. 4g-i), similarly to rapamycin in the brains of Ndufs $4 \mathrm{KO}$ mice $^{54}$. These findings suggest that mitochondrial dysfunction and associated pathology in the brains of $\mathrm{KO}$ mice leads to an innate immune and inflammatory response, which is strongly suppressed with doxycycline treatment.

The identification of antibiotics as potential drug-targeted therapies for MDs is highly paradoxical. Due to the close homology of the translational machinery in prokaryotes and human mitochondria, antibiotics designed to target the prokaryotic ribosome often induce dysregulation of both mitochondrial translation and organelle function in general ${ }^{16}$. Antibiotic-dependent survival occurs at concentrations that reduce but not block mitochondrial translation, supporting a mitohormesis model ${ }^{22}$. Although the precise downstream mechanisms are unclear, our results suggest that antibiotic-selective mitochondrial translation attenuation suppresses cell death and neuroimmune and inflammatory processes (Fig. 4j). Despite this, we acknowledge that in vivo neuroimmune activation may be regulated independently of mitochondrial translation and instead be sensitive to changes in the gut microbiome ${ }^{55,56}$.
Although further studies are needed, our data suggest that tetracyclines might constitute a potential intervention to ameliorate symptoms for MDs. Tetracycline SAR studies could also be used to identify improved analogues to treat MDs. Doxycycline is yet another example, along with rapamycin and hypoxia ${ }^{13,57}$, showing that complex I activity is not required to rescue pathologies associated with MDs. Currently, there are no clinically effective therapies for MDs; therefore, understanding the mechanisms downstream of antibiotic-dependent mitochondrial translation inhibition is valuable as a cell survival rescue process for MD mutations and future therapeutic strategies.

\section{Methods}

Cell lines and culture media conditions. MELAS cybrid cells, a gift of C. Moraes (University of Miami Medical School), were generated through the fusion of fibroblasts from a MELAS patient harbouring the $\mathrm{A} 3243 \mathrm{G}$ point mutation in MT-TL1 with a U2OS-based cell depleted of mitochondria ${ }^{10}$. ND1 and ND6 cybrid cells, previously studied by our laboratory ${ }^{17,33,37}$, were created by R. Vogel and J. Smeitink (Radboud University Medical Centre) using the same method described for the MELAS cybrid cells. In this case, ND1 and ND6 cybrid cells were made using patient fibroblasts carrying the A3796G mutation and ND6 G14459A, respectively. Control cybrids share the same U2OS nuclear background, but contain wild-type DNA. Rieske KO fibroblasts were a gift of C. Moraes and generated from mouse lung fibroblasts containing a knock-in allele with loxP sites flanking exon 2 of the Rieske protein (ISP $)^{16}$. High-glucose experiments were performed using $25 \mathrm{mM}$ glucose DMEM (Hyclone, SH30022.01) supplemented with 10\% FBS (GeminiBio, 900-208), $1 \mathrm{mM}$ sodium pyruvate (Gibco, 11360070), penicillin-streptomycin $\left(100 \mathrm{U} \mathrm{ml}^{-1}\right.$; Gibco, 15140148), $25 \mathrm{mM}$ HEPES buffer (Gibco, 15630080) and $50 \mu \mathrm{g} \mathrm{ml} \mathrm{m}^{-1}$ uridine (Sigma-Aldrich, U3003). For low-glucose experiments, $2.5 \mathrm{mM}$ glucose (Sigma, G8270) and $22.5 \mathrm{mM}$ galactose (Sigma-Aldrich, G5388) were added to no glucose DMEM (Gibco, 11966025) supplemented with 10\% FBS, $1 \mathrm{mM}$ sodium pyruvate, penicillin-streptomycin $\left(100 \mathrm{U} \mathrm{ml}^{-1}\right), 25 \mathrm{mM} \mathrm{HEPES}$ and $50 \mu \mathrm{g} \mathrm{ml}^{-1}$ 


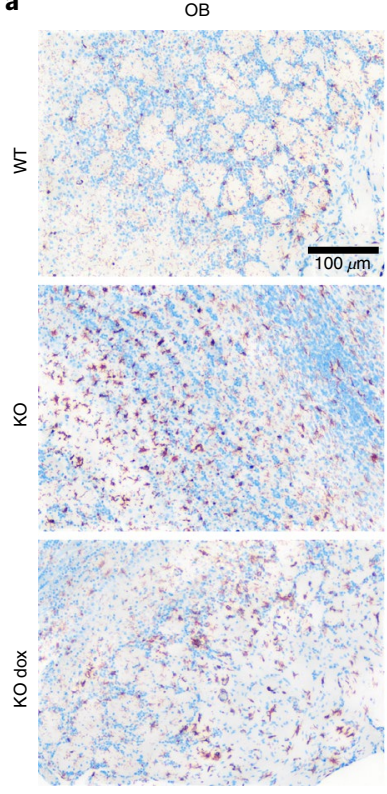

VN

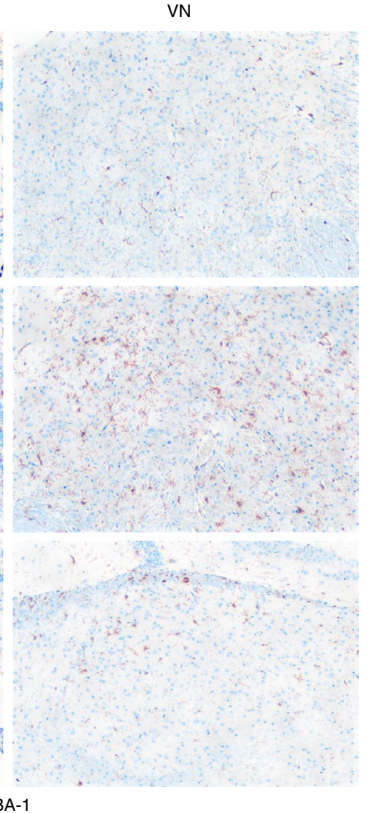

g

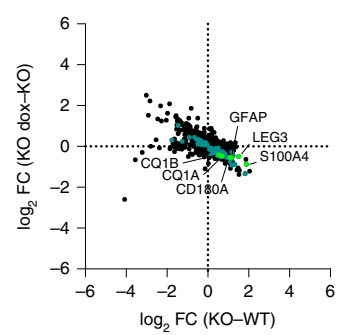

b
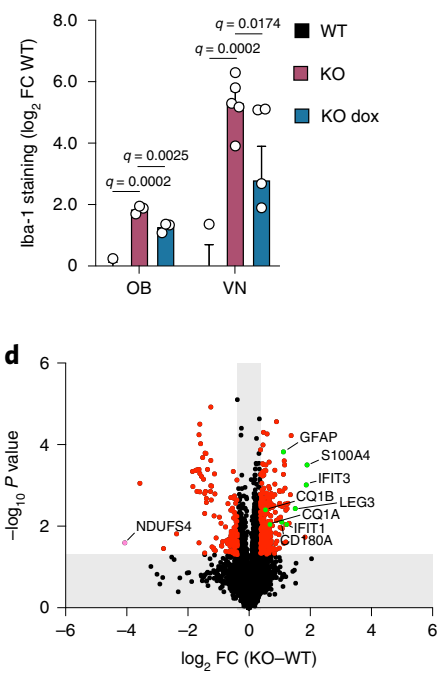

c
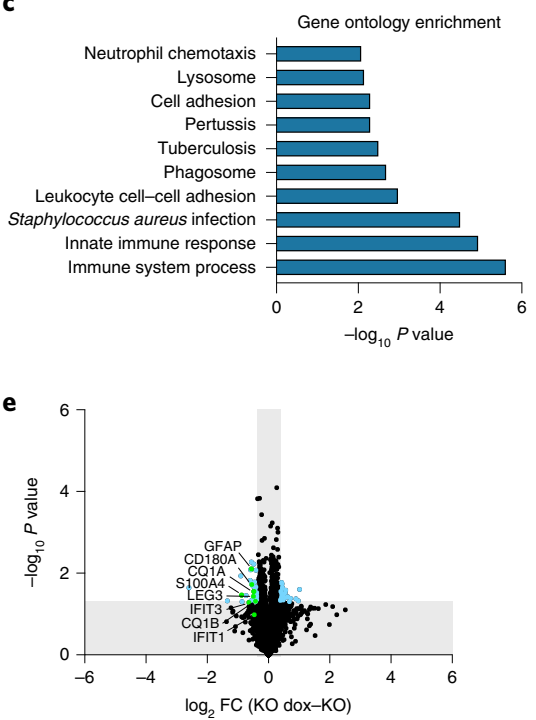

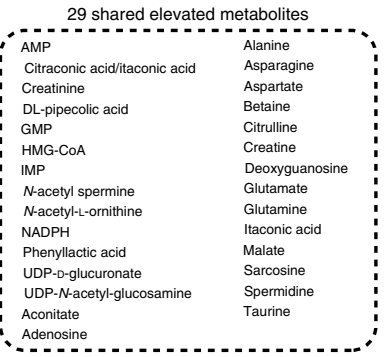

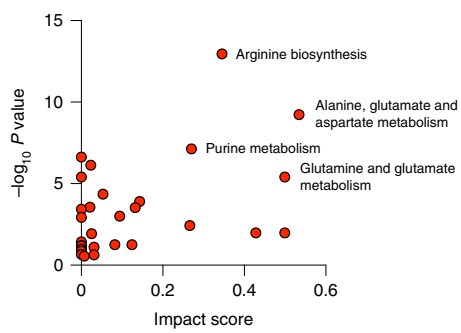

i

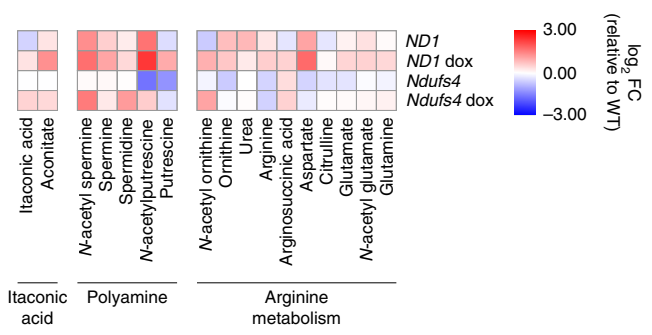

j
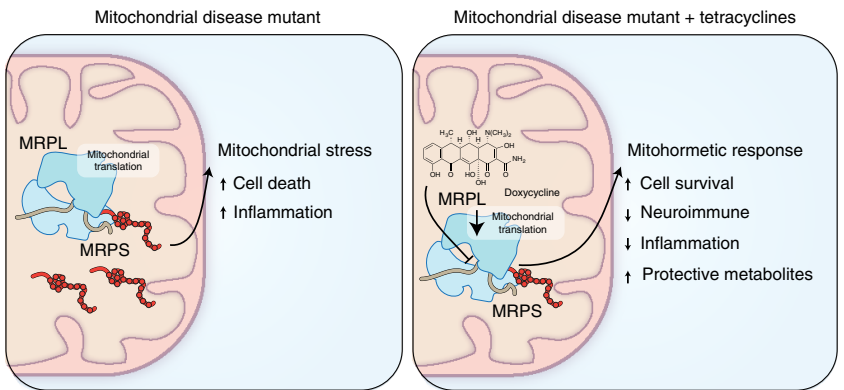

Fig. 4 | Doxycycline corrects neuroimmune and inflammatory proteins and increases metabolites that suppress oxidative stress in models of complex I deficiency. a,b, Representative images and quantification of $I b a-1$ staining in the olfactory bulb $(\mathrm{OB})$ and vestibular nucleus (VN) regions of the brain at $~ P 55$. Scale bar: $100 \mu \mathrm{m}$. (OB: $n=3$ mice for all groups; VN: $n=3 \mathrm{WT}, n=5 \mathrm{KO}$ and $n=5 \mathrm{KO}$ dox 5,000 p.p.m. mice; Student's $t$-test with a two-stage linear step-up procedure of Benjamini, Krieger and Yekutieli, with $Q=5 \%$ ). c, Gene ontology analysis of proteomic data from doxycycline-treated KO mice (Fisher's exact test). d, Volcano plot of proteomic changes in Ndufs $4^{-/-}$mouse brains. Annotated dots indicate proteins associated with astrocyte activation, microglial activation or interferon response (unpaired Student's $t$-test, two-sided). e, Volcano plot of proteomic changes in mouse brains of Ndufs $4^{-/}$mice treated with 5,000 p.p.m. doxycycline (unpaired Student's $t$-test, two-sided). f, Correlation plot of proteomic changes in KO mice (versus WT) compared to KO mice treated with doxycycline (versus KO). Points in green are significant changes in both comparisons $(P<0.05$, unpaired Student's $t$-test, two-sided). $\mathbf{g}$, Venn diagrams of metabolites increased by doxycycline in ND1 cybrid cells or Ndufs $4^{-/-}$mice $(P<0.15$, unpaired Student's $t$-test, two-sided). HMG, 3-hydroxy-3-methylglutaryl. h. Pathway analysis of metabolomic changes from doxycycline treatment in ND1 cybrid cells and Ndufs4 ${ }^{-/-}$ mice. $\mathbf{i}$, Heat map of individual metabolites of specific pathways upregulated by doxycycline in ND1 cybrid cells and Ndufs $4^{-/-}$mouse brains. $\mathbf{j}$, Model of antibiotics causing a mitohormetic response. Data in $\mathbf{b}$ are the mean \pm s.e.m.

uridine. For galactose conditions, $25 \mathrm{mM}$ galactose was added to no glucose DMEM supplemented with $10 \% \mathrm{FBS}, 1 \mathrm{mM}$ sodium pyruvate, penicillin-streptomycin $100 \mathrm{U}$ $\mathrm{ml}^{-1}, 25 \mathrm{mM}$ HEPES and $50 \mu \mathrm{g} \mathrm{ml^{-1 }}$ uridine.
High-throughput chemical screen. A high-throughput small-molecule screen for cell survival in MELAS cybrid cells was performed in collaboration with the Institute of Chemistry and Cell Biology (ICCB) at Harvard Medical School. 
MELAS cybrids were seeded at a density of 1,500 cells per well in DMEM supplemented with $2.5 \mathrm{mM}$ glucose, $22.5 \mathrm{mM}$ galactose, $4 \mathrm{mM}$ glutamine, $10 \%$ FBS and $50 \mu \mathrm{g} \mathrm{ml}^{-1}$ uridine. For each 384-well plate, two columns were used as positive controls containing cells grown in $25 \mathrm{mM}$ glucose medium. Chemical compounds were added by pin transfer at the time of seeding (final concentration of $3.3 \mu \mathrm{M}$ ). Under these conditions, untreated MELAS cells in $2.5 \mathrm{mM}$ glucose die after $24 \mathrm{~h}$, while those in $25 \mathrm{mM}$ glucose proliferate. The plates were measured for ATP luminescence (CellTiter-Glo, Promega, G7573) $48 \mathrm{~h}$ after seeding as a read-out of cell survival. After $48 \mathrm{~h}$, negative control wells were completely dead. In contrast, positive hits allowed the cells to survive with limited glucose. A total of 4,937 known bioactive compounds were screened from a diverse background. The screen was performed in technical duplicate so that each compound was added to two separate experimental wells on two separate plates. The $z$-score was calculated based on comparing an experimental well to the population mean on that plate. An average $z$-score was calculated for each compound and a cut-off of 1.96 (97.5\% confidence interval) was used to determine positive hits.

\section{Cell survival experiments. MELAS cybrid cells and Rieske KO fibroblasts} were seeded in $2.5 \mathrm{mM}$ glucose with $22.5 \mathrm{mM}$ galactose medium at a density of $1.0 \times 10^{5}$ cells per well in six-well plates. ND1 and ND6 mutant cybrid cells were seeded in $25 \mathrm{mM}$ galactose medium with $0 \mathrm{mM}$ glucose at a density of $1.0 \times 10^{5}$ cells per well in six-well plates. Stocks of doxycycline hyclate (Sigma, D9891), pentamidine isethionate (Sigma, 1504900) and retapamulin (Sigma, CDS023386) were dissolved in DMSO at $100 \mathrm{mM}$. Compounds were added to wells at the time of seeding at a final concentration of $1-100 \mu \mathrm{M}$. The p38 inhibitor SB203580 (Cell Signaling, 5633S) was dissolved in DMSO and used at a final concentration of $25 \mu \mathrm{M}$ as previously described ${ }^{33}$. MELAS and Rieske KO cells were counted after $48 \mathrm{~h}$ of incubation, unless otherwise noted. ND1 and ND6 were maintained for the indicated time point with galactose $(0 \mathrm{mM}$ glucose $)$ medium. For long-term survival experiments in low-glucose (for example, MELAS/Rieske cells) or galactose (for example, ND1/ND6 cells) medium, fresh medium and drug were replaced every 24 or $48 \mathrm{~h}$.

DNA isolation. The DNA isolation protocol was adapted from previous publications ${ }^{58,59}$. MELAS, ND1 or control cybrid cells were seeded at a density of $1.0 \times 10^{5}$ cells per well in $25 \mathrm{mM}$ glucose, $2.5 \mathrm{mM}$ glucose or galactose medium and harvested after $24 \mathrm{~h}$. Cells were washed with PBS, pelleted, resuspended in $0.5 \mathrm{ml}$ of $1 \times \mathrm{PBS}+0.5 \%$ SDS, mixed with $10 \mu \mathrm{l}$ of $20 \mathrm{mg} \mathrm{ml}^{-1}$ proteinase $\mathrm{K}$ and incubated for $1 \mathrm{~h}$ at $55^{\circ} \mathrm{C}$. Following incubation, $0.5 \mathrm{ml}$ phenol/chloroform was added, and samples were vortexed for $1 \mathrm{~min}$ and centrifuged at maximum speed for $5 \mathrm{~min}$. The aqueous layer was then transferred to a new tube and $50 \mu \mathrm{l}$ of $3 \mathrm{M}$ sodium acetate (pH 5.2) was added, followed by $1.5 \mathrm{ml}$ ice-cold ethanol. DNA was precipitated overnight at $-80^{\circ} \mathrm{C}$. After thawing, DNA was pelleted at maximum speed for $30 \mathrm{~min}$. The supernatant was carefully removed and the pellets were air dried for $10 \mathrm{~min}$. The pellets were resuspended in $200 \mu \mathrm{l}$ of water and RNase was added to a final concentration of $5 \mu \mathrm{g} \mathrm{ml}{ }^{-1}$, and samples were incubated at $37^{\circ} \mathrm{C}$ for $30 \mathrm{~min}$.

Heteroplasmy PCR. PCR was performed from mtDNA using primers flanking ND1 or MT-TL1. PCR primer sequences were as follows: ND1 forward 5'-CCTAGGCCTCCTATTT-3', ND1 reverse 5' -CGGCGTATTCGATGT-3', MT-TL1 forward 5'-GGTTCGTTTGTTCAACGATT- $3^{\prime}$ and MT-TL1 reverse 5'-TGCCATTGCGATTAGAATGG-3'. Each reaction contained $15 \mathrm{ng}$ template DNA, $12.5 \mu \mathrm{l}$ Q5 reaction buffer (New England Biolabs, M0491), $10 \mu \mathrm{M}$ forward and reverse primers and water up to $25 \mu$ l. The following protocol was performed: $98^{\circ} \mathrm{C}$ for $30 \mathrm{~s}, 98^{\circ} \mathrm{C}$ for $10 \mathrm{~s}, 57^{\circ} \mathrm{C}$ (ND1)/62 ${ }^{\circ} \mathrm{C}$ (MT-TL1) for $30 \mathrm{~s}$ followed by $72^{\circ} \mathrm{C}$ for $15 \mathrm{~s}$ (with the last three steps repeated 29 times), $72^{\circ} \mathrm{C}$ for $2 \mathrm{~min}$ and held at $10^{\circ} \mathrm{C}$. A restriction digest was performed on the PCR products from MELAS, ND1 and control cybrids. MELAS and control cybrids were digested with Apall (New England Biolabs, R0114S) and ND1 and control cybrids were digested with Acil (New England Biolabs, R0551S). The reactions were incubated for $1 \mathrm{~h}$ at $37^{\circ} \mathrm{C}$ and run on a $2 \%$ agarose gel.

Oxygen consumption measurements. For oxygen consumption measurements for cells, $1.0 \times 10^{5}$ cells were seeded in an XFE-24 Seahorse plate (Seahorse Biosciences, $102340-100$ ) and allowed to adhere for $24 \mathrm{~h}$ at $37^{\circ} \mathrm{C}$ with $5 \% \mathrm{CO}_{2}$. DMEM was then removed and cells were washed twice with pre-warmed unbuffered DMEM supplemented with $25 \mathrm{mM}$ glucose, $1 \mathrm{mM}$ sodium pyruvate and $4 \mathrm{mM}$ glutamine. After washing, $500 \mu \mathrm{l}$ of identical buffer was added and the cells were then placed in a $\mathrm{CO}_{2}$ free incubator for $1 \mathrm{~h}$. The Seahorse 24 optical fluorescent analyser cartridge was prepared by adding $4 \mu \mathrm{M}$ oligomycin, $4 \mu \mathrm{M}$ carbonyl cyanide 4-(trifluoromethoxy)phenylhydrazone and $1.5 \mu \mathrm{M}$ rotenone $/ 4 \mu \mathrm{M}$ antimycin A to cartridge ports A, B and C, respectively. Oxygen consumption rates $(\mathrm{pmol} \mathrm{min}-1)$ were measured for each treatment condition at $37^{\circ} \mathrm{C}$ using the Seahorse Bioanalyzer instrument with the following protocol: $\mathrm{mix}$ for $1 \mathrm{~min}$, wait for $3 \mathrm{~min}$ and measure for $3 \mathrm{~min}$.

Mitochondrial isolations and solubilizations for blue native PAGE. Mitochondrial isolations and blue native PAGE (BN-PAGE) were performed as previously described ${ }^{60,61}$. Frozen cell pellets were thawed on ice in hypotonic buffer ( $83 \mathrm{mM}$ sucrose, $10 \mathrm{mM}$ MOPS, $1 \times$ cOmplete EDTA-free Protease Inhibitor Cocktail (Roche, 4693159001)) and subsequently homogenized using a dounce homogenizer. After this, osmolarity was normalized using hypertonic sucrose buffer and the resulting solution was centrifuged at $1,000 \mathrm{~g}$ for $5 \mathrm{~min}$. The supernatant was then centrifuged for a second time to remove cell debris. Next, the supernatant containing mitochondria was centrifuged at $9,000 \mathrm{~g}$ for $10 \mathrm{~min}$. The mitochondrial pellet was resuspended and washed twice in resuspension buffer (320 mM sucrose, $1 \mathrm{mM}$ EDTA, $10 \mathrm{mM}$ Tris ( $\mathrm{pH} 7.4$ ) and $1 \times$ protease inhibitor cocktail (Roche, 4693159001)). The protein content of each mitochondrial preparation was quantified and mitochondria were divided into 100-200 $\mu \mathrm{g}$ aliquots that were flash frozen. Before running BN-PAGE, mitochondria were solubilized in NativePAGE $4 \times$ Sample Buffer (Thermo Fisher Scientific, BN2003) at a $6 \mathrm{~g} / \mathrm{g}$ digitonin to protein ratio for $20 \mathrm{~min}$ on ice. The insoluble portion was removed by centrifugation for $15 \mathrm{~min}$ at maximum speed. The soluble supernatant was then mixed with Coomassie G-250 (Thermo Fisher Scientific, BN2004) before BN-PAGE.

Immunoblot. Cells or tissue were harvested in RIPA buffer $(10 \mathrm{mM}$ Tris- $\mathrm{HCl}$ ( $\mathrm{pH} 8.00,1 \mathrm{mM}$ EDTA, $1 \%$ Triton X-100, 0.1\% sodium deoxycholate, $0.1 \%$ SDS, $140 \mathrm{mM} \mathrm{NaCl}, 1 \times$ protease inhibitor cocktail and $1 \mathrm{mM}$ PMSF) and proteins were quantified using the BCA assay (Pierce 23228). BN-PAGE analysis of $6 \mathrm{~g} / \mathrm{g}$ digitonin/protein solubilized mitochondrial preparations was performed using 3-12\% NativePAGE gels (Thermo Fisher Scientific, BN1003BOX) according to the manufacturer's instructions. Then, $20 \mu \mathrm{g}$ of protein was run per well. BN-PAGE buffers included NativePAGE Running Buffer (20×; Thermo Fisher Scientific, BN2001) and NativePAGE Cathode Buffer Additive (20x; Thermo Fisher Scientific, BN2002). After electrophoresis, proteins and/or complexes were transferred to PVDF membranes and probed with specific antibodies. The following antibodies and dilutions were used for SDS-PAGE and BN-PAGE: anti-SDHA (1:3,000; Abcam, ab14715), anti-MTCO1 (1:3,000; Abcam, ab14705), anti-NDUFA9 (1:1,000; Abcam, ab14713), anti-NDUFS2 (1:1,000; Abcam, 192022), anti-UQCRB (1:1,000; Proteintech, 10756-1-AP), anti-ATP5A1 (1:1,000; Life Technologies, 459240), anti-ATF4 (1:1,000; Cell Signaling, 11815), anti- $\beta$-actin (1:2,000; Cell Signaling, 4967), p-eIF2 $\alpha$ (1:1,000; Ser 51; Cell Signaling, 3398), total eIF2 $\alpha$ (1:1,000; Cell Signaling, 5324), anti-CHOP (1:1,000; Cell Signaling, 2895), anti- $\beta$-tubulin (1:5,000; Cell Signaling, 2146$)$, anti-MRPL4 (1:1,000; Proteintech, 27484-1-AP), anti-GFM2 (1:1,000; Proteintech, 16941-1-AP) and anti-PAR1 $(1: 1,000 ;$ Abcam, ab32611).

Depletion of mtDNA with ethidium bromide. EtBr solution (Bio-Rad, 1610433) was diluted to $50 \mu \mathrm{g} \mathrm{ml}^{-1}$ with water and sterile filtered. ND1 cybrid cells cultured in glucose supplemented with $50 \mu \mathrm{g} \mathrm{ml}^{-1}$ uridine were treated with $50 \mathrm{ng} \mathrm{ml}^{-1} \mathrm{EtBr}$ with medium replaced daily as described previously ${ }^{17,27}$. After 3 weeks of treatment, EtBr-treated and untreated ND1 cybrid cells were seeded at a density of $1.0 \times 10^{5}$ cells per well in galactose medium with $1 \mu \mathrm{M}$ doxycycline or DMSO and counted after $48 \mathrm{~h}$.

siRNA transfections. siRNA oligonucleotide duplexes for ATF4 and F2R were purchased from Origene (ATF4, SR319410; F2R, SR301496). The three siRNA guides were pooled and resuspended at a final concentration of $20 \mu \mathrm{M}$. For each infection, $6 \mu$ l lipofectamine RNAi Max (Thermo Fisher Scientific, 13778100) was added to $100 \mu \mathrm{l}$ Opti-MEM medium (Thermo Fisher Scientific, 31985088) followed by vortexing and left at room temperature for $5 \mathrm{~min}$. In a separate tube, $1 \mu \mathrm{l}$ of the resuspended RNAi was added to $100 \mu \mathrm{l}$ Opti-MEM and vortexed. Both tubes were then combined and added directly to a six-well plate. Lastly, $1.0 \times 10^{5}$ cells in $2 \mathrm{ml}$ of medium were added to the well.

CRISPR gene-editing experiments. CRISPR-Cas9 editing was performed using the GeCKO system ${ }^{62}$. Guides were cloned into the lentiCRISPRv2 plasmid containing puromycin resistance (Addgene, 98290). After cloning, HEK293T cells were reverse transfected in six-well plates using PolyFect (Qiagen, 301105) following the manufacturer's instructions. Transfection reactions contained $600 \mathrm{ng}$ of psPAX2 (Addgene, 12260), $300 \mathrm{ng}$ of pMD2 (Addgene, 12259) and $900 \mathrm{ng}$ of lentiCRISPRV 2 with control guide RNAs. At $24 \mathrm{~h}$ after transfection, the medium was replaced with fresh DMEM ( $3 \mathrm{ml}$ per well). The next day, medium was collected, filtered through a $0.45-\mu \mathrm{m}$ filter and poured into ND1 cybrid cells grown from an overnight six-well culture ( $1 \times 10^{5}$ seeding density). At $24 \mathrm{~h}$ after the infection, the medium was replaced with fresh medium. Cells were selected $48 \mathrm{~h}$ after infection with $0.5 \mu \mathrm{g} \mathrm{mll}{ }^{-1}$ puromycin and selection continued for 2 weeks before cells were used for experiments. Guides for CRISPR-Cas9 editing can be found in Supplementary Table 8.

Measurement of mitochondrial translation. ND1 mutant cybrid cells cultured in glucose for $48 \mathrm{~h}$ in the presence of compound were washed with PBS and incubated for $30 \mathrm{~min}$ in $1 \mathrm{ml}$ of labelling medium ( $1 \mathrm{mM}$ sodium pyruvate in DMEM without methionine and cysteine) in the presence of compound. Emetine was added to a final concentration of $200 \mathrm{\mu g} \mathrm{ml}^{-1}$, and cells were incubated for an additional $30 \mathrm{~min}$ before the addition of $50 \mu \mathrm{Ci}^{35} \mathrm{~S}$-labelled methionine/cysteine mixture for $1 \mathrm{~h}$. Cells were recovered and washed twice in PBS before lysis and 
protein quantification. Next, $5 \mu \mathrm{g}$ of total proteins in a volume of $10 \mu \mathrm{l}$ was loaded onto $4-12 \%$ SDS-PAGE. Cells treated with chloramphenicol $\left(50 \mu \mathrm{g} \mathrm{ml}^{-1}\right)$ were used as a negative control to ensure the mitochondrial origin of the ${ }^{35} \mathrm{~S}$ signal. The protein identification associated with each band was proposed based on their relative abundance and molecular weight as determined by previous studies ${ }^{63}$. Mitochondrial band intensities were quantified using ImageJ software v1.52 by plotting lanes and calculating the area under the curve with a signal threshold set to a non-protein section of the blot.

Gene expression. RNA was isolated with Trizol (Invitrogen, 15596-026) and a Zymo-Spin Direct-zol RNA Kit (Zymo Research, R2050). Then, $1 \mu \mathrm{g}$ of RNA was used to generate cDNA with a High-Capacity cDNA Reverse Transcription Kit (Applied Biosystems, 4368813) following the manufacturer's protocol. For gene expression analysis, cDNA samples were mixed with Sybr Green quantitative PCR master mix (Applied Biosystems, 4309155) and were analysed by a CFX 384 Real-Time system (Bio-Rad). All primers sequences can be found in Supplementary Table 8 .

Animal care and lifespan determination. C57BL/6J mice heterozygous for the $N d u f_{s} 4$ gene were purchased from the Jackson Laboratory (B6.129S4-Ndufs $4^{\text {tm1.1Rpa }} / \mathrm{J}$, 027058) and crossed to generate $N d u f s 4^{-/-}$mice. Mice were housed in the Beth Israel Deaconess Medical Center Animal Facility and kept on a 12-h light/dark cycle. The facility was maintained at $20-22^{\circ} \mathrm{C}$ and $50 \%$ humidity. Pups were weaned at P21 and genotyped immediately. $N d u f_{s} 4^{-/-}$mice were randomly assigned to a treatment group along with 1-2 wild-type or heterozygous littermate controls. Males and females were included equally in all experiments and distributed equally amongst the treatment groups. Mice were given standard chow supplemented with 5,000 p.p.m. doxycycline, 8,000 p.p.m. doxycycline or a re-pelleted control diet (OpenSource Diets). Additional food and hydrogel were placed on the floor of the cage and replaced every $48 \mathrm{~h}$. The cages were inspected daily, and mice were weighed every $48 \mathrm{~h}$ to determine peak body weight. Mice were humanly euthanized with $\mathrm{CO}_{2}$ according to the Institutional Animal Care and Use Committee protocol when body weight declined by more than $20 \%$ of maximum (at that time, littermate controls were also euthanized). All animal studies were compliant with the Institutional Animal Care and Use Committee protocol approved by the Beth Israel Deaconess Medical Center Animal Facility.

Rotarod testing. Motor function was assessed using a rotarod test at P30, P40 and P50 ( $\pm 2 \mathrm{~d})$. One day before the P30 test, mice were acclimatized to the rotarod. $\mathrm{KO}$ and WT littermate control mice were each placed on the rod and the latency to fall was measured for up to $5 \mathrm{~min}$ using an acceleration of 4 r.p.m. per minute and a maximum speed of 40 r.p.m. Mice were considered to have fallen if they latched onto the rotarod for more than $10 \mathrm{~s}$ without walking. The test was performed three times and the maximum of the three attempts was reported. A minimum of five mice were tested for each time point and each group.

Histology. $\mathrm{KO}$ and littermate control mice were euthanized with $\mathrm{CO}_{2}$ and the entire head was removed. The skin was removed from the head, a sagittal cut was made into the posterior cranium and the skull was lifted slightly away from the brain. The entire head was submerged into $10 \%$ formalin for $48 \mathrm{~h}$ and then transferred to dilute formalin (1:10 dilution of formalin in PBS) for storage until processing. Samples were submitted to the Harvard Medical School Rodent Histopathology Core for paraffin embedding, parasagittal sectioning and $\mathrm{H} \& \mathrm{E}$ staining. Unstained sections were submitted to the Specialized Histopathology Core at Brigham and Women's Hospital for immunohistochemistry. Antibody IBA-1 (Wako, 019-19741; polyclonal) was run at a 1:500 dilution using the Leica Biosystems Refine Detection Kit with citrate antigen retrieval and Alexa 488 (Thermo Fisher Scientific, B40953). Sections were imaged at the Nikon Facility at Harvard Medical School using Nikon Ds-Fil cooled colour digital microscope camera with Nikon Plan Apochromat $\times 20$ 0.75 NA objective. Additional sections were imaged at the Brigham and Women's Specialized Histopathology Core using the Leica Aperio Versa 200 slide scanner. Staining quantification was performed using ImageJ. Briefly, images were background subtracted (rolling ball radius, 200), colour deconvoluted, thresholded (Huang) and measured for integrated density of thresholded signal.

Metabolomics. Brain tissue was collected from $\mathrm{KO}$ and littermate control mice at $\sim 55 \mathrm{~d}$ of age and stored at $-80^{\circ} \mathrm{C}$ before metabolite extraction. Frozen tissues were powderized using liquid nitrogen and a mortar and pestle. Next, $800 \mu \mathrm{l}$ of $60 \%$ cold methanol was used to resuspend $10 \mathrm{mg}$ of powdered tissue. The samples were vortexed periodically for $10 \mathrm{~min}$ and returned to ice. Then, $500 \mu \mathrm{l}$ of cold chloroform was added to each sample and vortexing continued for an additional $10 \mathrm{~min}$. Samples were centrifuged at maximum speed for $10 \mathrm{~min}$ at $4^{\circ} \mathrm{C}$. The top layer, which contains the polar metabolites, was removed and transferred to a new tube and dried down overnight using a SpeedVac (Thermo Fisher Scientific). For cells, $1.0 \times 10^{5} \mathrm{ND} 1$ or U2OS control cybrid cells were seeded in each well of a six-well plate and cultured in galactose medium for $48 \mathrm{~h}$. Cells (three wells in each replicate) were harvested on dry ice with $0.8 \mathrm{ml}$ of pre-chilled $80 \%$ HPLC-grade methanol (Fluka Analytical). The cell mixture was incubated for $15 \mathrm{~min}$ on dry ice before centrifugation at $18,000 \mathrm{~g}$ for $10 \mathrm{~min}$ at $4^{\circ} \mathrm{C}$. The supernatant was retained, and the remaining cell pellet was resuspended in $200 \mu \mathrm{l}$ of pre-chilled $80 \%$ methanol and centrifuged. Supernatants were combined and lyophilized using a SpeedVac. Lyophilized samples, from both brains and cells, were resuspended in $20 \mu \mathrm{l}$ HPLC quality water and subjected to metabolomics profiling using the AB/SCIEX 5500 QTRAP triple quadrupole instrument. Data analysis was performed using the GiTools software. $P$ values are from MetaboAnalyst pathway enrichment and impact scores are from pathway topology analysis.

\section{Protein digestion and isobaric labelling for mass spectrometry analysis. Brain} tissues were extracted and snap frozen in liquid nitrogen until further use. Brain tissues were lysed with $4 \mathrm{ml}$ of SDS lysis buffer (2.0\% SDS (wt/vol), $250 \mathrm{mM} \mathrm{NaCl}$, $5 \mathrm{mM}$ TCEP, EDTA-free protease inhibitor cocktail (Promega) and $100 \mathrm{mM}$ HEPES $(\mathrm{pH} 8.5)$ ) using an Omni tissue homogenizer. Extracts were reduced at $57^{\circ} \mathrm{C}$ for $30 \mathrm{~min}$ and cysteine residues were alkylated with iodoacetamide $(14 \mathrm{mM})$ in the dark at room temperature for $45 \mathrm{~min}$. Extracts were purified by methanolchloroform precipitation and pellets were washed with ice-cold methanol. Pellets were resuspended in $2 \mathrm{ml}$ of $8 \mathrm{M}$ urea (containing $50 \mathrm{mM}$ HEPES at $\mathrm{pH} 8.5$ ), and protein concentrations were measured by BCA assay (Thermo Fisher Scientific) before protease digestion. Then, $100 \mu \mathrm{g}$ of protein was diluted to $4 \mathrm{M}$ urea and digested overnight with $4 \mu \mathrm{g}$ LysC (Wako). Digests were diluted further to a $1.5 \mathrm{M}$ urea concentration, and $5 \mu \mathrm{g}$ of trypsin (Promega) was added for $6 \mathrm{~h}$ at $37^{\circ} \mathrm{C}$. Digests were acidified with $50 \mu \mathrm{l}$ of $20 \%$ formic acid and subsequently desalted by C18 solid-phase extraction ( $50 \mathrm{mg}$; Sep-Pak, Waters). Digested brain peptides were resuspended in $100 \mu \mathrm{l}$ of $200 \mathrm{mM}$ HEPES ( $\mathrm{pH} 8.0$ ). Next, $10 \mu \mathrm{l}$ of TMTpro reagents (Thermo Fisher Scientific) was added to each solution for $1 \mathrm{~h}$ at room temperature $\left(25^{\circ} \mathrm{C}\right)$. After incubating, the reaction was quenched by adding $4 \mu \mathrm{l}$ of $5 \%$ (wt/vol) hydroxylamine. Labelled peptides were combined and subsequently desalted by $\mathrm{C} 18$ solid-phase extraction ( $50 \mathrm{mg}$; Sep-Pak, Waters) before basic $\mathrm{pH}$ reversed-phase separation.

\section{Basic pH reverse-phase separation for mass spectrometry analysis. Tandem} mass tag (TMT)-labelled peptides were solubilized in $500 \mu \mathrm{l}$ of solution containing $5 \%$ acetonitrile in $10 \mathrm{mM}$ ammonium bicarbonate $(\mathrm{pH} 8.0)$ and separated by an Agilent 300 Extend C18 column (5-mm particles, 4.6-mm inner diameter and 220 -mm in length). An Agilent 1100 binary pump coupled with a photodiode array detector (Thermo Fisher Scientific) was used to separate the peptides. A 40 -min linear gradient from $20 \%$ to $40 \%$ acetonitrile in $10 \mathrm{mM}$ ammonium bicarbonate ( $\mathrm{pH} 8$; flow rate of $0.6 \mathrm{ml} \mathrm{min}^{-1}$ ) separated the peptide mixtures into a total of 96 fractions ( $30 \mathrm{~s}$ ). A total of 96 fractions was consolidated into 12 samples in a chequerboard fashion, acidified with $20 \mu \mathrm{l}$ of $20 \%$ formic acid and vacuum dried to completion. Each sample was re-dissolved in 5\% formic acid, 5\% ACN, desalted via StageTips before liquid chromatography-tandem mass spectrometry $\left(\mathrm{MS}^{2}\right)$ analysis.

\section{Liquid chromatography-tandem mass spectrometry analysis. Data were} collected using an Orbitrap Fusion Lumos mass spectrometer (Thermo Fisher Scientific) coupled with a Proxeon EASY-nLC 1200 LC pump (Thermo Fisher Scientific). Peptides were separated on a $100-\mu \mathrm{m}$ inner diameter microcapillary column packed with $35 \mathrm{~cm}$ of Accucore C18 resin $(2.6 \mu \mathrm{m}, 100 \AA$; Thermo Fisher Scientific). Peptides were separated using a 3-h gradient of $6-22 \%$ acetonitrile

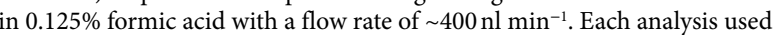
a triple-stage mass spectrometry $\left(\mathrm{MS}^{3}\right)$-based TMT method as described previously ${ }^{40}$. Data were acquired using a mass range of $\mathrm{m} / z 400-1400$, a resolution of 120,000 , an automatic gain control (AGC) target of $1 \times 10^{6}$, a maximum injection time of $100 \mathrm{~ms}$ and a dynamic exclusion of $180 \mathrm{~s}$ for the peptide measurements in the Orbitrap. Data-dependent $\mathrm{MS}^{2}$ spectra were acquired in the ion trap with a normalized collision energy set at $35 \%$, an AGC target set to $2.0 \times 10^{5}$ and a maximum injection time of $120 \mathrm{~ms}$. $\mathrm{MS}^{3}$ scans were acquired in the Orbitrap with a higher-energy collisional dissociation collision energy set to 45\%, an AGC target set to $1.5 \times 10^{5}$, a maximum injection time of $200 \mathrm{~ms}$, a resolution of 50,000 and a maximum synchronous precursor selection activated for ten precursors.

Mass spectrometry data processing and spectra assignment. In-house developed software was used to convert acquired mass spectrometric data from the .RAW file to the mzXML format. Erroneous assignments of peptide ion charge state and monoisotopic $\mathrm{m} / z$ were also corrected by the internal software. SEQUEST algorithm was used to assign $\mathrm{MS}^{2}$ spectra by searching the data against a protein sequence database including Mouse Uniprot Database (downloaded June 2018) and known contaminants such as mouse albumin and human keratins. A forward (target) database component was followed by a decoy component including all listed protein sequences. Searches were performed using a precursor ion tolerance of 20 p.p.m. and requiring both peptide termini to be consistent with trypsin specificity. The 16-plex TMT labels on lysine residues and peptide $\mathrm{N}$ termini $(+304.2071 \mathrm{Da})$ were set as static modifications and oxidation of methionine residues $(+15.99492 \mathrm{Da})$ as a variable modification. An $\mathrm{MS}^{2}$ spectra assignment false discovery rate (FDR) of less than $1 \%$ was implemented by applying the target-decoy database search strategy. Filtering was performed using a linear discrimination analysis method to create one combined filter parameter from 
the following peptide ion and MS2 spectra properties: XCorr and $\Delta C n$, peptide ion mass accuracy and peptide length. Linear discrimination scores were used to assign probabilities to each $\mathrm{MS}^{2}$ spectrum for being assigned correctly, and these probabilities were further used to filter the dataset with an $\mathrm{MS}^{2}$ spectra assignment FDR to obtain a protein identification FDR of less than $1 \%$.

Determination of TMT reporter ion intensities. For reporter ion quantification, a $0.003 \mathrm{~m} / z$ window centred on the theoretical $\mathrm{m} / z$ value of each reporter ion was monitored for ions, and the maximum intensity of the signal to the theoretical $\mathrm{m} / \mathrm{z}$ value was recorded. Reporter ion intensities were normalized by multiplication with the ion accumulation time for each $\mathrm{MS}^{2}$ or $\mathrm{MS}^{3}$ spectrum and adjusted based on the overlap of isotopic envelopes of all reporter ions. Following extraction of the reporter ion signal, the isotopic impurities of the TMT reagent were corrected using the values specified by the manufacturer's specification. Total signal-to-noise values for all peptides were summed for each TMT channel, and all values were adjusted to account for variance and a total minimum signal-to-noise value of 200 was implemented.

Measurement of doxycycline from tissues. Doxycycline extraction was modified from a previous protocol ${ }^{64}$. Brain and liver from P55 WT and KO mice treated with 5,000 p.p.m. and 8,000 p.p.m. was powderized using a mortar and pestle. Approximately $100 \mathrm{mg}$ of tissue was homogenized using a bead beater in $1 \mathrm{ml}$ $0.02 \mathrm{M}$ oxalic acid buffer ( $\mathrm{pH} 4.0$ ). For standard curves, brain or liver ( $1 \mathrm{~g}$ each) from untreated control mice were powderized and homogenized in oxalic acid buffer $(10 \mathrm{ml})$. The sample was divided into $10 \times 1 \mathrm{ml}$ samples to which doxycycline at known concentrations was added. These samples were processed identically to doxycycline-treated mouse samples. Then, $50 \mu \mathrm{l}$ of $2 \mu \mathrm{M}$ doxycycline D3 standard (Cayman, 28528) was added to each sample and vortexed. Samples were centrifuged at max speed for $10 \mathrm{~min}$, and the supernatant was transferred to a $15-\mathrm{ml}$ tube. The pellet was resuspended in $1 \mathrm{ml}$ oxalic buffer for a second extraction, which was pooled with the first following homogenization and centrifugation. Next, $250 \mu \mathrm{l}$ of $20 \%$ trichloroacetic acid was added to each sample, vortexed and centrifuged at maximum speed for $15 \mathrm{~min}$. SPE columns (Strata SPE, $8 \mathrm{~B}$-S100-ECH) were conditioned using $3 \mathrm{ml}$ methanol followed by $3 \mathrm{ml} \mathrm{HCL}$ and then $3 \mathrm{ml}$ of water. Sample supernatants were transferred onto the conditioned cartridges and allowed to flow through. The cartridges were then washed with $3 \mathrm{ml}$ oxalic acid buffer followed by $2 \mathrm{ml}$ of water and then dried completely by opening the vacuum and letting air pass through the cartridges for $10 \mathrm{~min}$. For elution, $10-\mathrm{ml}$ tubes were placed below the vacuum manifold and $5 \mathrm{ml}$ methanol was added to each cartridge. Samples were dried completely in a SpeedVac and submitted to the Harvard Center for Mass Spectrometry for processing. Samples were quantified on a QEplus mass spectrometer coupled to an Ultimate 3000 LC (Thermo Fisher Scientific). After resuspension in $50 \mu \mathrm{l}$ of water, $10 \mu \mathrm{l}$ was injected on a Luna C18 column $(2 \mathrm{~mm} \times 150 \mathrm{~mm}$; Phenomenex $)$ maintained at $40^{\circ} \mathrm{C}$. The mobile phases were: $\mathrm{A}$, water and $0.1 \%$ formic acid; $\mathrm{B}$, acetonitrile and $0.1 \%$ formic acid. The gradient was as follows: $5 \% \mathrm{~B}$ for $1 \mathrm{~min}$, then to $60 \% \mathrm{~B}$ in $1 \mathrm{~s}$, maintained at $60 \%$ $\mathrm{B}$ for $11 \mathrm{~min}$, then to $90 \% \mathrm{~B}$ in $1 \mathrm{~s}$, maintained at $90 \%$ for $3 \mathrm{~min}$, followed by $5 \mathrm{~min}$ re-equilibration at $5 \% \mathrm{~B}$. The flow rate was $0.2 \mathrm{ml} \mathrm{min}^{-1}$. Two standard curves were prepared by adding various concentration of doxycycline in blank liver or brain samples. The standard points were then extracted in the same way as the samples. Quantification was achieved with Tracefinder (Thermo Fisher Scientific), using the ratio of the area under the peak for doxycycline and of the internal standard, using the accurate mass of the $[\mathrm{M}+\mathrm{H}]^{+}$ions.

Statistical analysis and reproducibility. All measurements were taken from distinct biological samples. For mapping of restriction fragment length polymorphisms and SDS-PAGE or BN-PAGE western blots, $n=1$ experiments were performed unless otherwise noted. In general, for two experimental comparisons, a two-tailed unpaired Student's $t$-test was used. For multiple comparisons to a control, we used Student's $t$-test with a two-stage linear step-up procedure of Benjamini, Krieger and Yekutieli, with $Q=5 \%$. Statistical significance is represented by asterisks corresponding to ${ }^{*} p / q<0.05$. GraphPad Prism software (version 8.4.0) was used to generate graphs and perform statistical analyses. Microsoft Excel for Mac (version 16.43) was used for analysis of small-molecule screen data, metabolomics and proteomics. Morpheus software from the Broad Institute (https://software.broadinstitute.org/morpheus/) was used to generate heat maps. DAVID Bioinformatics Resources 6.8 was used for gene ontology analysis ${ }^{65,66}$. The mitochondrial ribosomal structure in Fig. 21 was generated with UCSF ChimeraX ${ }^{67}$.

Reporting Summary. Further information on research design is available in the Nature Research Reporting Summary linked to this article.

\section{Data availability}

Datasets generated during this study are included as Supplementary Information or are publicly available. Chemical screen data have been deposited in PubChem under accession 1508586 and proteomic data in PRIDE under accession PXD022860. Source data are provided with this paper. Any additional data not included in this manuscript are available from the corresponding author upon request.
Received: 12 June 2020; Accepted: 10 December 2020; Published online: 18 January 2021

\section{References}

1. Area-Gomez, E. \& Schon, E. A. Mitochondrial genetics and disease. J. Child Neurol. 29, 1208-1215 (2014).

2. Wallace, D. C. \& Chalkia, D. Mitochondrial DNA genetics and the heteroplasmy conundrum in evolution and disease. Cold Spring Harb. Perspect. Biol. 5, a021220 (2013).

3. El-Hattab, A. W., Adesina, A. M., Jones, J. \& Scaglia, F. MELAS syndrome: clinical manifestations, pathogenesis and treatment options. Mol. Genet. Metab. 116, 4-12 (2015).

4. Gorman, G. S, et al. Mitochondrial diseases. Nat. Rev. Dis. Primers 2, 16080 (2016).

5. El-Hattab, A. W., Zarante, A. M., Almannai, M. \& Scaglia, F. Therapies for mitochondrial diseases and current clinical trials. Mol. Genet. Metab. 122, 1-9 (2017).

6. Pfeffer, G., Majamaa, K., Turnbull, D. M., Thorburn, D. \& Chinnery, P. F. Treatment for mitochondrial disorders. Cochrane Database Syst. Rev. https://doi.org/10.1002/14651858.CD004426.pub3 (2012).

7. Russell, O. M., Gorman, G. S., Lightowlers, R. N. \& Turnbull, D. M. Mitochondrial diseases: hope for the future. Cell 181, 168-188 (2020)

8. Kruse, S. E. et al. Mice with mitochondrial complex I deficiency develop a fatal encephalomyopathy. Cell Metab. 7, 312-320 (2008).

9. Sproule, D. M. \& Kaufmann, P. Mitochondrial encephalopathy, lactic acidosis and stroke-like episodes. Ann. NY Acad. Sci. 1142, 133-158 (2008).

10. Srivastava, S. et al. PGC- $1 \alpha / \beta$-induced expression partially compensates for respiratory chain defects in cells from patients with mitochondrial disorders. Hum. Mol. Genet. 18, 1805-1812 (2009)

11. Pallotti, F. et al. Biochemical analysis of respiratory function in cybrid cell lines harbouring mitochondrial DNA mutations. Biochem. J. 384, 287-293 (2004)

12. Khan, N. A. et al. mTORC1 regulates mitochondrial integrated stress response and mitochondrial myopathy progression. Cell Metab. 26, 419-428 (2017)

13. Johnson, S. C. et al. mTOR inhibition alleviates mitochondrial disease in a mouse model of Leigh syndrome. Science 342, 1524-1528 (2013).

14. Civiletto, G. et al. Rapamycin rescues mitochondrial myopathy via coordinated activation of autophagy and lysosomal biogenesis. EMBO Mol. Med. 10, e8799 (2018).

15. Yu, A. K., Datta, S., McMackin, M. Z. \& Cortopassi, G. A. Rescue of cell death and inflammation of a mouse model of complex 1-mediated vision loss by repurposed drug molecules. Hum. Mol. Genet. 26, 4929-4936 (2017).

16. Diaz, F., Enríquez, J. A. \& Moraes, C. T. Cells lacking Rieske iron-sulfur protein have a reactive oxygen species-associated decrease in respiratory complexes I and IV. Mol. Cell. Biol. 32, 415-429 (2012).

17. Barrow, J. J. et al. Bromodomain inhibitors correct bioenergetic deficiency caused by mitochondrial disease complex I mutations. Mol. Cell 64, 163-175 (2016)

18. Moullan, N. et al. Tetracyclines disturb mitochondrial function across eukaryotic models: a call for caution in biomedical research. Cell Rep. 10, 1681-1691 (2015).

19. Sun, T. \& Zhang, Y. Pentamidine binds to tRNA through non-specific hydrophobic interactions and inhibits aminoacylation and translation. Nucleic Acids Res. 36, 1654-1664 (2008).

20. Chukwudi, C. U. rRNA binding sites and the molecular mechanism of action of the tetracyclines. Antimicrob. Agents Chemother. 60, 4433-4441 (2016).

21. Meydan, S. et al. Retapamulin-assisted ribosome profiling reveals the alternative bacterial proteome. Mol. Cell 74, 481-493 (2019).

22. Yun, J. \& Finkel, T. Mitohormesis. Cell Metab. 19, 757-766 (2014).

23. Charest, M. G., Lerner, C. D., Brubaker, J. D., Siegel, D. R. \& Myers, A. G. A convergent enantioselective route to structurally diverse 6-deoxytetracycline antibiotics. Science 308, 395-398 (2005).

24. Sun, C. et al. A robust platform for the synthesis of new tetracycline antibiotics. J. Am. Chem. Soc. 130, 17913-17927 (2008).

25. Wright, P. M. \& Myers, A. G. Methodological advances permit the stereocontrolled construction of diverse fully synthetic tetracyclines containing an all-carbon quaternary center at position C5a. Tetrahedron 67, 9853-9869 (2011)

26. Golub, L. M., McNamara, T. F., D’Angelo, G., Greenwald, R. A. \& Ramamurthy, N. S. A non-antibacterial chemically modified tetracycline inhibits mammalian collagenase activity. J. Dent. Res. 66, 1310-1314 (1987)

27. Leibowitz, R. D. The effect of ethidium bromide on mitochondrial DNA synthesis and mitochondrial DNA structure in HeLa cells. J. Cell Biol. 51, 116-122 (1971)

28. Quirós, P. M. et al. Multi-omics analysis identifies ATF4 as a key regulator of the mitochondrial stress response in mammals. J. Cell Biol. 216 2027-2045 (2017). 
29. Alano, C. C., Kauppinen, T. M., Valls, A. V. \& Swanson, R. A. Minocycline inhibits poly(ADP-ribose) polymerase-1 at nanomolar concentrations. Proc. Natl Acad. Sci. USA 103, 9685-9690 (2006).

30. Zhong, W. et al. Doxycycline directly targets PAR1 to suppress tumor progression. Oncotarget 8, 16829-16842 (2017).

31. Golub, L. M. et al. Tetracyclines inhibit tissue collagenase activity. A new mechanism in the treatment of periodontal disease. J. Periodontal Res. 19, 651-655 (1984).

32. Jin, Z., Wei, W., Yang, M., Du, Y. \& Wan, Y. Mitochondrial complex I activity suppresses inflammation and enhances bone resorption by tipping the balance of macrophage-osteoclast polarization. Cell Metab. 20, 483-498 (2014).

33. Soustek, M. S. et al. Inhibition of the ER stress IRE1 $\alpha$ inflammatory pathway protects against cell death in mitochondrial complex I mutant cells. Cell Death Dis. 9, 658 (2018).

34. Lorenzl, S., Albers, D. S., Narr, S., Chirichigno, J. \& Beal, M. F. Expression of MMP-2, MMP-9 and MMP-1 and their endogenous counterregulators TIMP-1 and TIMP-2 in postmortem brain tissue of Parkinson's disease. Exp. Neurol. 178, 13-20 (2002).

35. Montero, R. et al. GDF-15 is clevated in children with mitochondrial diseases and is induced by mitochondrial dysfunction. PLoS One 11, e0148709 (2016).

36. Sliter, D. A. et al. Parkin and PINK1 mitigate STING-induced inflammation. Nature 561, 258-262 (2018).

37. Balsa, E. et al. Defective NADPH production in mitochondrial disease complex I causes inflammation and cell death. Nat. Commun. 11, 2714 (2020).

38. Lake, N. J., Compton, A. G., Rahman, S. \& Thorburn, D. R. Leigh syndrome: one disorder, more than 75 monogenic causes. Ann. Neurol. 79, 190-203 (2016).

39. Gengenbacher, M. et al. Tissue distribution of doxycycline in animal models of tuberculosis. Antimicrob. Agents Chemother. 64, e02479-19 (2020).

40. McAlister, G. C. et al. MultiNotch $\mathrm{MS}^{3}$ enables accurate, sensitive and multiplexed detection of differential expression across cancer cell line proteomes. Anal. Chem. 86, 7150-7158 (2014).

41. Stephan, A. H., Barres, B. A. \& Stevens, B. The complement system: an unexpected role in synaptic pruning during development and disease. Annu. Rev. Neurosci. 35, 369-389 (2012).

42. Torres-Odio, S. et al. Progression of pathology in PINK1-deficient mouse brain from splicing via ubiquitination, ER stress and mitophagy changes to neuroinflammation. J. Neuroinflammation 14, 154 (2017).

43. Benninger, F., Glat, M. J., Offen, D. \& Steiner, I. Glial fibrillary acidic protein as a marker of astrocytic activation in the cerebrospinal fluid of patients with amyotrophic lateral sclerosis. J. Clin. Neurosci. 26, 75-78 (2016).

44. Liuyu, T. et al. Induction of OTUD4 by viral infection promotes antiviral responses through deubiquitinating and stabilizing MAVS. Cell Res. 29, 67-79 (2019).

45. Dodd, M. E. et al. The ENTH domain protein Clint 1 is required for epidermal homeostasis in zebrafish. Development 136, 2591-2600 (2009).

46. Zhang, Y. et al. Effect of ApoA4 on SERPINA3 mediated by nuclear receptors NR4A1 and NR1D1 in hepatocytes. Biochem. Biophys. Res. Commun. 487, 327-332 (2017).

47. Lampropoulou, V. et al. Itaconate links inhibition of succinate dehydrogenase with macrophage metabolic remodeling and regulation of inflammation. Cell Metab. 24, 158-166 (2016)

48. Pegg, A. E. Functions of polyamines in mammals. J. Biol. Chem. 291, 14904-14912 (2016).

49. Ying, W. $\mathrm{NAD}^{+} / \mathrm{NADH}$ and $\mathrm{NADP}^{+} / \mathrm{NADPH}$ in cellular functions and cell death: regulation and biological consequences. Antioxid. Redox Signal. 10, 179-206 (2008).

50. Medina, C. B. et al. Metabolites released from apoptotic cells act as tissue messengers. Nature 580, 130-135 (2020).

51. Madeo, F., Eisenberg, T., Pietrocola, F. \& Kroemer, G. Spermidine in health and disease. Science 359, eaan2788 (2018).

52. Holmström, K. M. \& Finkel, T. Cellular mechanisms and physiological consequences of redox-dependent signalling. Nat. Rev. Mol. Cell Biol. 15, 411-421 (2014).

53. Suomalainen, A. \& Battersby, B. J. Mitochondrial diseases: the contribution of organelle stress responses to pathology. Nat. Rev. Mol. Cell Biol. 19, 77-92 (2018).

54. Johnson, S. C. et al. Regional metabolic signatures in the $N d u f_{s} 4(K O)$ mouse brain implicate defective glutamate/ $\alpha$-ketoglutarate metabolism in mitochondrial disease. Mol. Genet. Metab. 130, 118-132 (2020).

55. Cerovic, M., Forloni, G. \& Balducci, C. Neuroinflammation and the gut microbiota: possible alternative therapeutic targets to counteract Alzheimer's disease? Front. Aging Neurosci. 11, 284 (2019).

56. Sampson, T. R. et al. Gut microbiota regulate motor deficits and neuroinflammation in a model of Parkinson's disease. Cell 167, 1469-1480 (2016).
57. Ferrari, M. et al. Hypoxia treatment reverses neurodegenerative disease in a mouse model of Leigh syndrome. Proc. Natl Acad. Sci. USA 114, E4241-E4250 (2017).

58. Teves, S. S. \& Henikoff, S. Transcription-generated torsional stress destabilizes nucleosomes. Nat. Struct. Mol. Biol. 21, 88-94 (2014).

59. Belaghzal, H., Dekker, J. \& Gibcus, J. H. Hi-C 2.0: an optimized Hi-C procedure for high-resolution genome-wide mapping of chromosome conformation. Methods 123, 56-65 (2017).

60. Jha, P., Wang, X. \& Auwerx, J. Analysis of mitochondrial respiratory chain supercomplexes using blue native polyacrylamide gel electrophoresis (BN-PAGE). Curr. Protoc. Mouse Biol. 6, 1-14 (2016).

61. Balsa, E. et al. ER and nutrient stress promote assembly of respiratory chain supercomplexes through the PERK-eIF2 $\alpha$ axis. Mol. Cell 74, 877-890 (2019).

62. Shalem, O. et al. Genome-scale CRISPR-Cas9 knockout screening in human cells. Science 343, 84-87 (2014).

63. Sasarman, F. \& Shoubridge, E. A. Radioactive labeling of mitochondrial translation products in cultured cells. Methods Mol. Biol. 837, 207-217 (2012)

64. Gajda, A., Posyniak, A. \& Tomczyk, G. LC-MS/MS analysis of doxycycline residues in chicken tissues after oral administration. Bull. Vet. Inst. Pulawy 58, 573-579 (2014).

65. Huang, D. W., Sherman, B. T. \& Lempicki, R. A. Systematic and integrative analysis of large gene lists using DAVID bioinformatics resources. Nat. Protoc. 4, 44-57 (2009).

66. Huang, D. W., Sherman, B. T. \& Lempicki, R. A. Bioinformatics enrichment tools: paths toward the comprehensive functional analysis of large gene lists. Nucleic Acids Res. 37, 1-13 (2009).

67. Pettersen, E. F. et al. UCSF ChimeraX: structure visualization for researchers, educators and developers. Protein Sci. https://doi.org/10.1002/pro.3943 (2020).

68. Rhee, H.-W. et al. Proteomic mapping of mitochondria in living cells via spatially restricted enzymatic tagging. Science 339, 1328-1331 (2013).

69. RCSB PDB. 5AJ4: structure of the 55S mammalian mitoribosome. https://www.rcsb.org/structure/5AJ4.

\section{Acknowledgements}

We thank members of the Puigserver Laboratory for helpful discussions regarding this project. We also thank C. Moraes (University of Miami Medical School) and J. Smeitink and R. Vogel (Radboud University Medical Centre) for providing the cell lines used in this study. We acknowledge the Nikon Imaging Center at Harvard Medical School for assistance with brightfield microscopy; the ICCB-Longwood Screening Facility at Harvard Medical School for facilitating our screening efforts; J.M. Asara and M. Yuan at the Beth Israel Deaconess Medical Center Mass Spectrometry Core for providing metabolomics profiling data, R. Bronson and the Rodent Histopathology Core at Harvard Medical School for careful sectioning and analysis of mouse sections; and the Specialized Histopathology Core at Brigham and Women's Hospital for immunohistochemistry. We thank C. Vidoudez of the Harvard Center for Mass Spectrometry for analysis of doxycycline tissue concentrations. This work was supported by National Institutes of Health (NIH) grants RO1 DK089883-07 NIDDK and RO1 GM121452 NIGMS (to P.P.), F30 DE028206-01A1 NIDCR (to E.A.P.) and F32 GM125243-01A1 NIGMS (to C.F.B.), an EMBO postdoctoral fellowship and MDA Development Grant (to E.B.), and the Human Frontier Science Program (LT-000033/2019-L) to P.L.M.

\section{Author contributions}

Conceptualization: E.A.P., C.F.B. and P.P.; methodology: E.A.P. and C.F.B.; formal analysis: E.A.P. and C.F.B.; investigation: E.A.P., C.F.B., C.L., K.E.O., E.B., P.L.-M., M.J., R.P.L., K.R. and P.M.W.; resources: M.J., S.P.G., A.G.M. and P.P.; writing (original draft): E.A.P., C.F.B. and P.P.; writing (review and editing): E.A.P., C.F.B., P.P., K.E.O., E.A.P., E.B., P.L.-M., C.L., M.J., R.P.L., K.R., P.M.W., A.G.M. and P.P.; visualization: E.A.P. and C.F.B.; supervision: E.A.P., C.F.B. and P.P.; funding acquisition: E.A.P., C.F.B. and P.P.

\section{Competing interests}

The authors declare no competing interests.

\section{Additional information}

Extended data is available for this paper at https://doi.org/10.1038/s42255-020-00334-y.

Supplementary information is available for this paper at https://doi.org/10.1038/ s42255-020-00334-y.

Correspondence and requests for materials should be addressed to P.P.

Peer review information Primary Handling Editors: Christoph Schmitt, Pooja Jha. Nature Metabolism thanks Navdeep Chandel, Riekelt Houtkooper and the other, anonymous, reviewer(s) for their contribution to the peer review of this work.

Reprints and permissions information is available at www.nature.com/reprints. Publisher's note Springer Nature remains neutral with regard to jurisdictional claims in published maps and institutional affiliations.

(c) The Author(s), under exclusive licence to Springer Nature Limited 2021 
a.

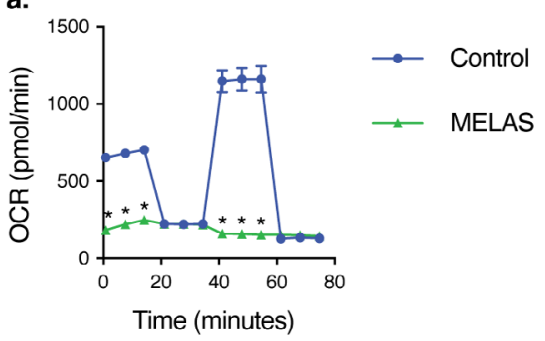

b.

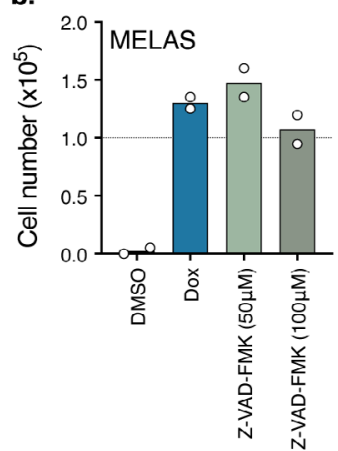

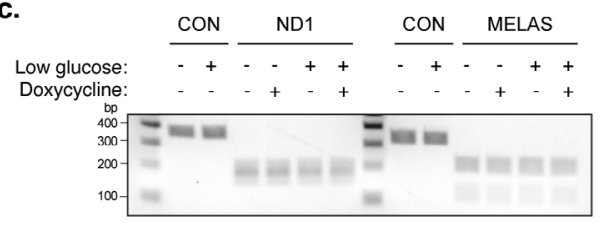

d.

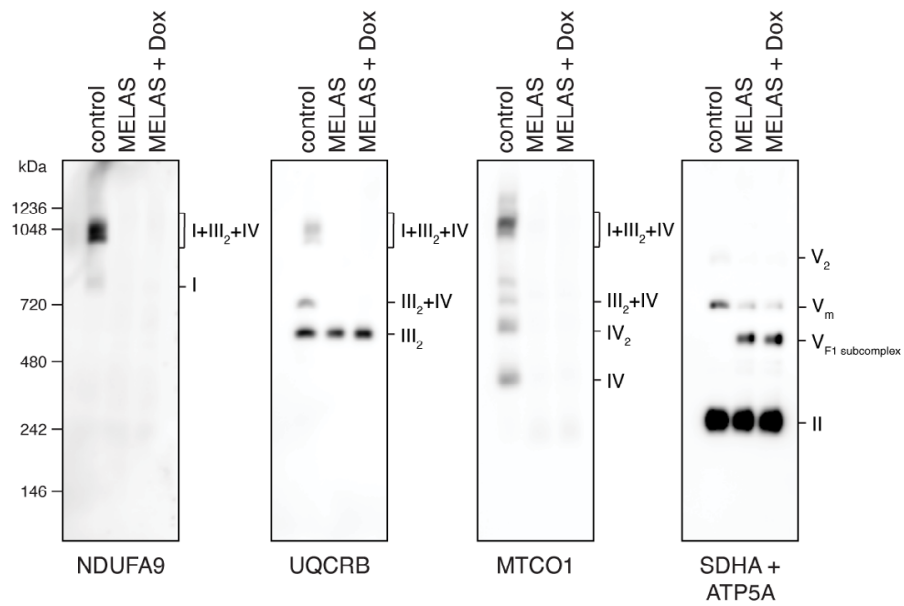

e.

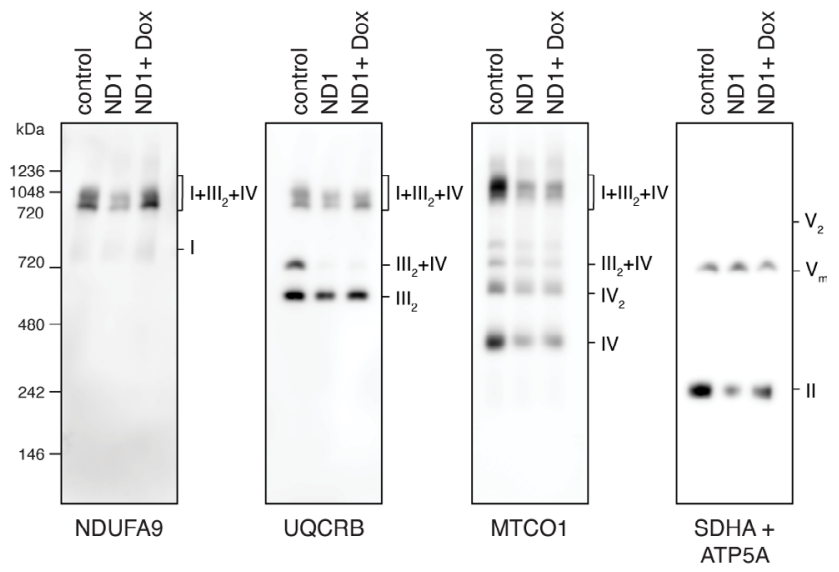

f.

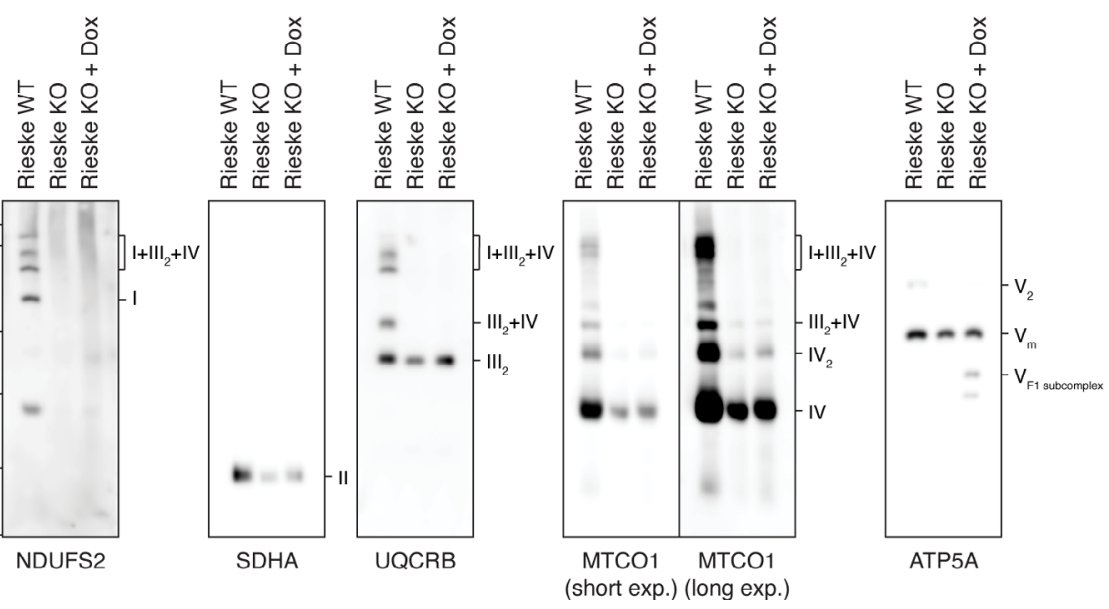

Extended Data Fig. 1 | MELAS cybrid cells exhibit deficient mitochondrial respiration and undergo apoptosis from nutrient stress. a, Oxygen Consumption Rates (OCR) measured in control and MELAS cybrid cells. Measurements 4-6 follow the injection of $4 \mu \mathrm{M}$ oligomycin, measurements 7-9 follow the injection of $4 \mu \mathrm{M} \mathrm{FCCP}$, and measurements $10-12$ follow the injection of $1.5 \mu \mathrm{M}$ rotenone/4 $\mu \mathrm{M}$ antimycin ( $n=5$ biologically independent samples). b, 48 hour low-glucose survival assay of MELAS cybrid cells treated with the pan-caspase inhibitor Z-VAD-FMK or doxycycline (Dox) ( $n=2$ biologically independent samples). c, RFLP mapping of ND1 and MELAS mtDNA mutations in cybrids after 24 hour galactose or low-glucose conditions with $1 \mu \mathrm{M}$ doxycycline. Expected band sizes are 193/159 bp for ND1 and 117/213 bp for MELAS mutations. d-f, BN-PAGE of isolated mitochondria from MELAS cybrids, ND1 cybrids, and Rieske KO fibroblasts treated with $1 \mu \mathrm{M}$ doxycycline. MELAS cybrids were propagated 24 hours in low-glucose media, ND1 cybrids were propagated for 48 hours in galactose media, and Rieske KO fibroblasts were propagated for 48 hours in high-glucose media. Data are presented as mean values \pm s.e.m. error bars, Student's t-test with a two-stage linear step-up procedure of Benjamini, Krieger and Yekutieli, with $Q=5 \%$, $~ q<0.05$. 
a.

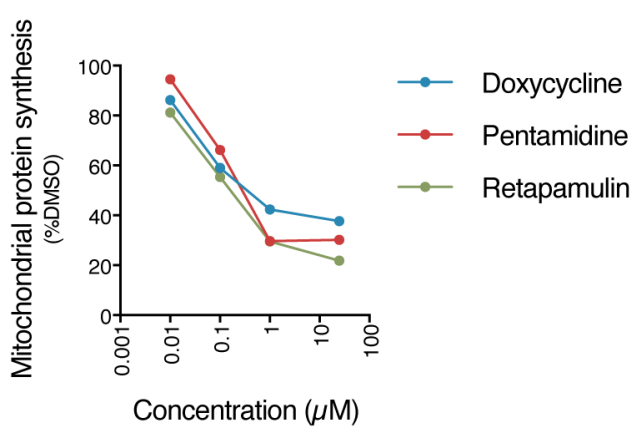

d.

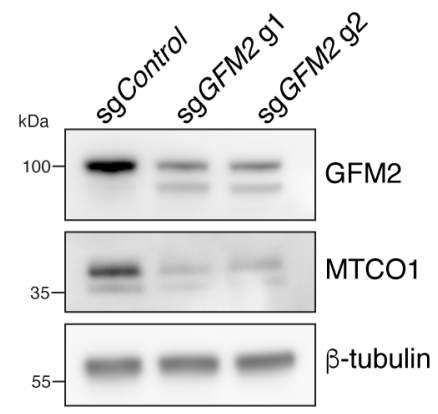

b.

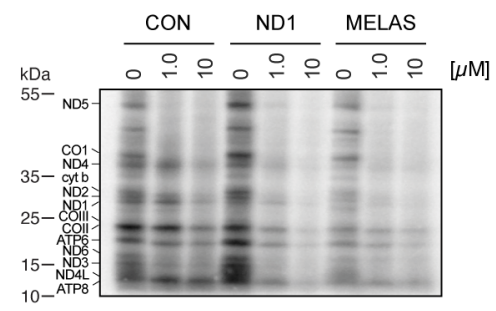

c.

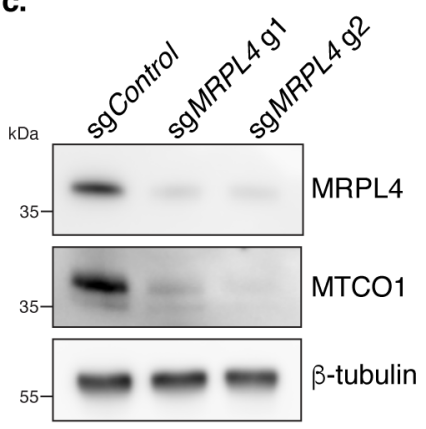

Extended Data Fig. 2 | Doxycycline promotes cell survival through attenuation of mitochondrial translation. a, Mitochondrial protein synthesis (\%DMSO) versus antibiotic concentration based on band quantification relative to DMSO from Fig. $2 b\left(n=2\right.$ experiments). $\mathbf{b}$, ${ }^{35} \mathrm{~S}$-labelled cysteine and methionine pulse in cybrid cells treated with doxycycline at $1 \mu \mathrm{M}$ or $10 \mu \mathrm{M}$ with a 48 hour pre-treatment and 1 hour pulse $(n=2$ experiments). c, Western blot of MRPL4 in sgMRPL4 ND1 cybrid cells. d, Western blot of GFM2 in sgGFM2 ND1 cybrid cells. 
a.
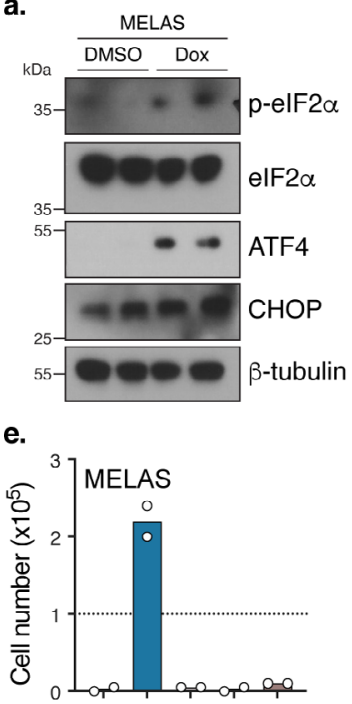

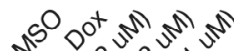

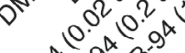

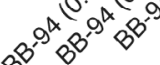

i.

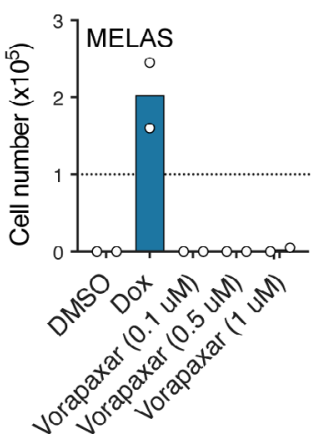

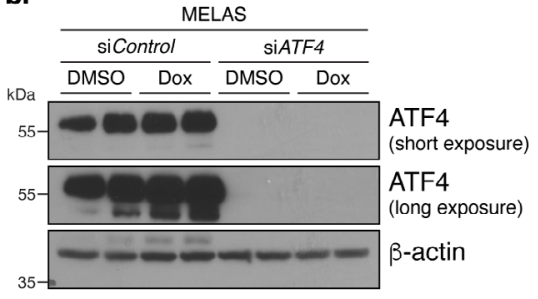

c.

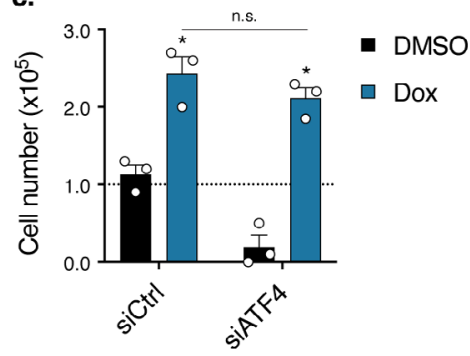

d.

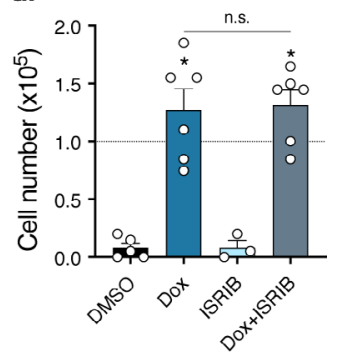

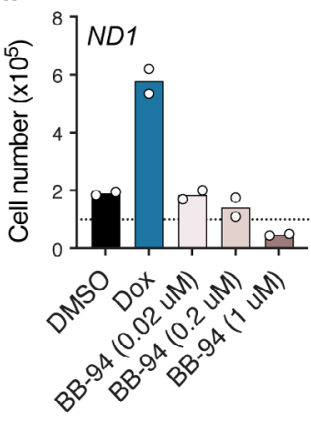

j.

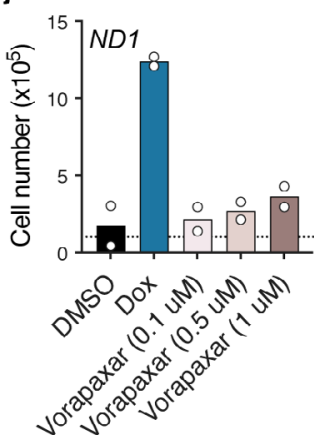

g.

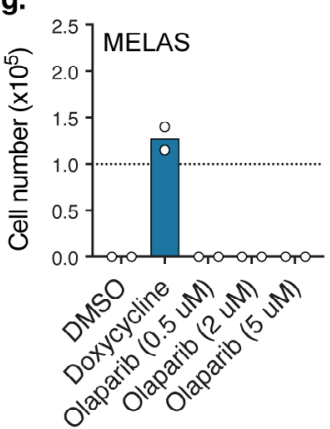

k.

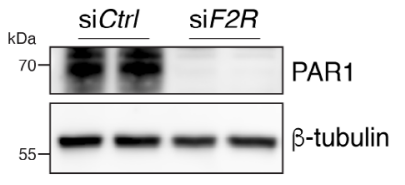

h.

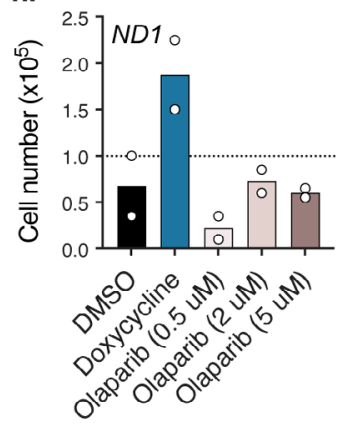

I.

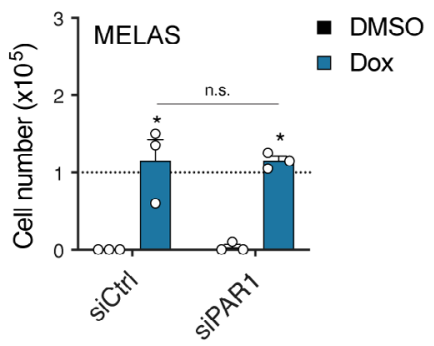

Extended Data Fig. 3 | Doxycycline does not promote cell survival in MELAS or ND1 cybrid cells through the integrated protein response (ATF4) or reported protein targets. a, Western blot of integrated response proteins in MELAS cybrid cells treated with doxycycline (Dox) for 24 hours ( $n=2$ experiments). b. Western blot of ATF4 in siATF4 MELAS cybrid cells $(n=2$ experiments). $\mathbf{c}$, 48 hour low-glucose survival of siATF4 MELAS cybrid cells treated with doxycycline ( $n=3$ biologically independent samples). d, 48 hour low-glucose survival of MELAS cybrid cells treated with doxycycline with or without ISRIB (Integrated Stress Response Inhibitor) ( $n=3$ biologically independent samples over $n=2$ independent experiments) e, 48 hour low-glucose survival of MELAS cybrid cells treated with pan matrix-metalloprotease (MMP) inhibitor BB-94 ( $n=2$ biologically independent samples). f, 4 day galactose survival assay of ND1 cybrid cells treated with BB-94 ( $n=2$ biologically independent samples). $\mathbf{g}$, 48 hour low-glucose survival of MELAS cybrid cells treated with the PARP inhibitor Olaparib ( $n=2$ biologically independent samples). $\mathbf{h}, 4$ day galactose survival of ND1 cybrid cells treated with Olaparib ( $n=2$ biologically independent samples). $\mathbf{i}, 48$ hour low-glucose survival of MELAS cybrid cells treated with the PAR1 inhibitor $\operatorname{Vorapaxar}(n=2$ biologically independent samples). $\mathbf{j}$, 8 day galactose survival of ND1 cybrid cells treated with Vorapaxar ( $n=2$ biologically independent samples). $\mathbf{k}$, Western blot of PAR1 in siF2R MELAS cybrid cells ( $n=2$ experiments). I, 48 hour low-glucose survival of MELAS cybrid cells depleted of PAR1 $(\mathrm{siF2R})(\mathrm{n}=3$ biologically independent samples). Data are presented as mean values \pm s.e.m. error bars, Student's t-test with a two-stage linear step-up procedure of Benjamini, Krieger and Yekutieli, with $Q=5 \%,{ }^{*} q<0.05$. 
a.

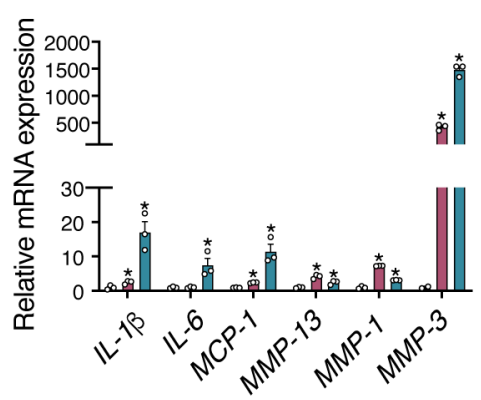

c.

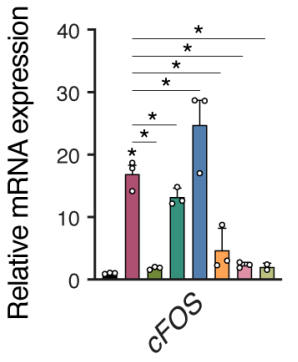

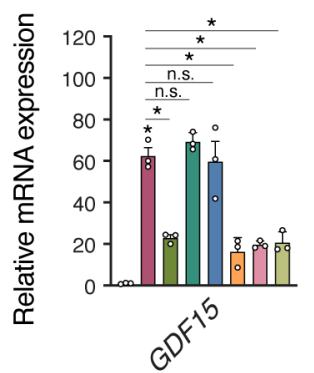
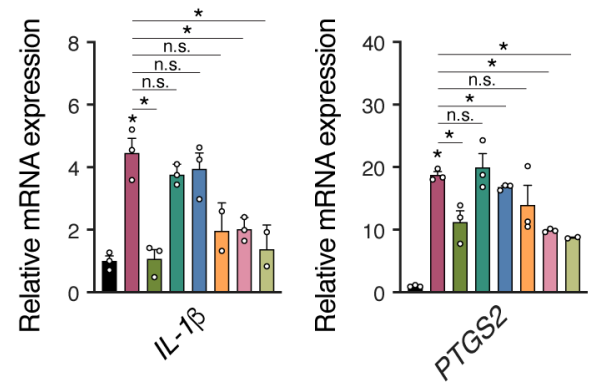

- ND1 glucose

- ND1 GAL + DMSO

- ND1 GAL + Dox

- ND1 GAL + CMT3

- ND1 GAL + 7004

$\square$ ND1 GAL + 7015

- ND1 GAL + 7039

$\square$ ND1 GAL + 7066

Extended Data Fig. 4 | Mitochondrial mutant cells have basally elevated cytokines under nutrient stress conditions which are suppressed by doxycycline. a, Gene expression of inflammatory cytokine panel under high-glucose conditions for control (CON), ND1, and MELAS cybrid cells ( $n=3$ biologically independent samples). b. Gene expression of inflammatory cytokines in MELAS cybrid cells after 24 hour low-glucose (LG) conditions ( $n=6$ biologically independent samples). c, Gene expression of inflammatory cytokines in ND1 cybrid cells after 48 hours galactose (GAL) conditions ( $n=3$ biologically independent samples). Tetracycline analogues that rescue cell survival such as doxycycline, 7015, 7039, and 7066 suppress inflammatory gene expression. Data are presented as mean values \pm s.e.m. error bars, Student's t-test with a two-stage linear step-up procedure of Benjamini, Krieger and Yekutieli, with $\mathrm{Q}=5 \%,{ }^{*} q<0.05$. 
a.

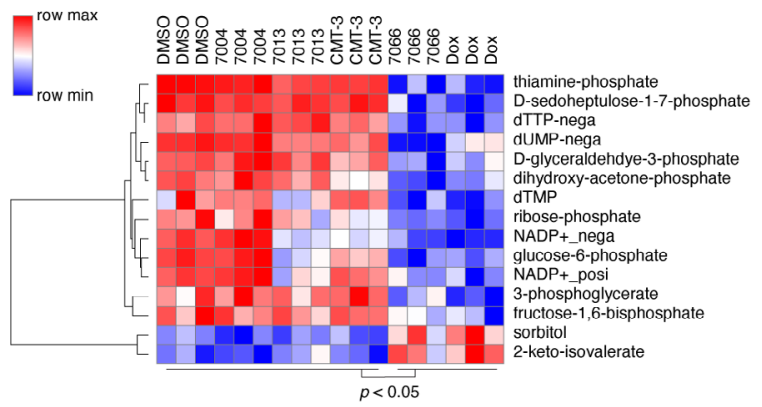

c.

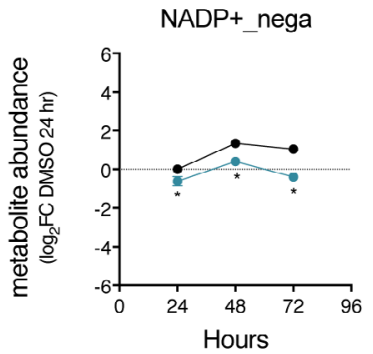

D-glyceraldehdye-3-phosphate

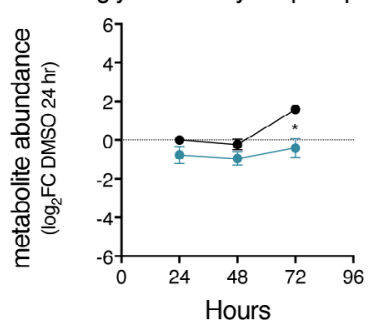

D-sedoheptulose-1-7-phosphate

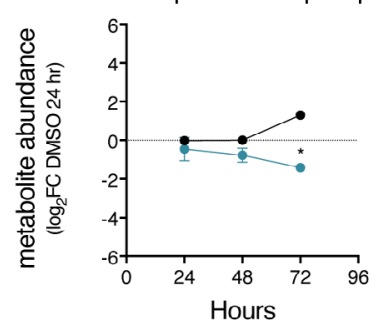

thiamine-phosphate

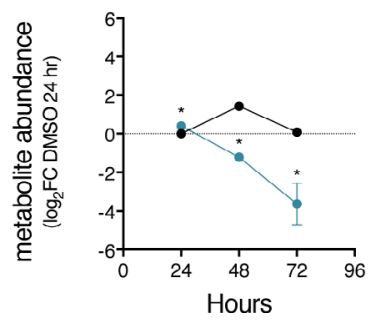

NADP+ posi

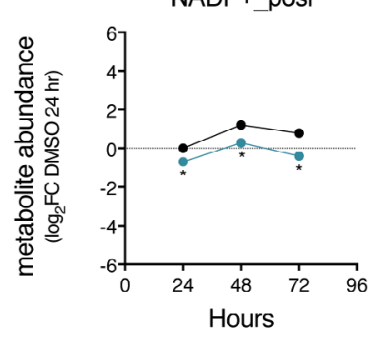

3-phosphoglycerate

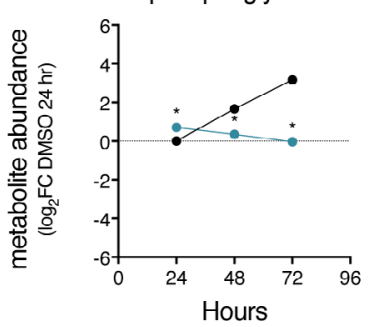

dUMP-nega

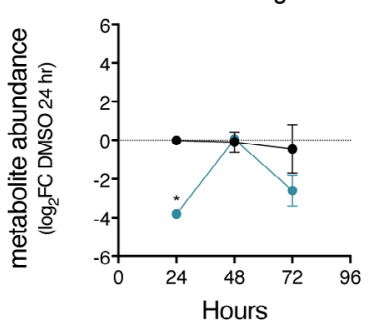

sorbitol

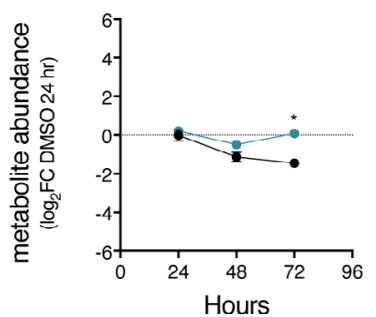

b.
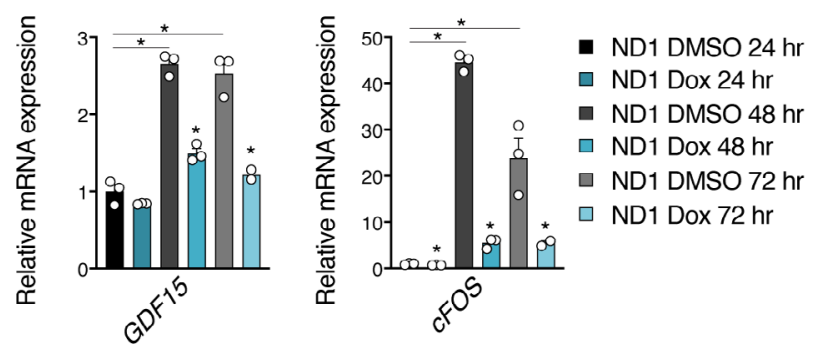

glucose-6-phosphate
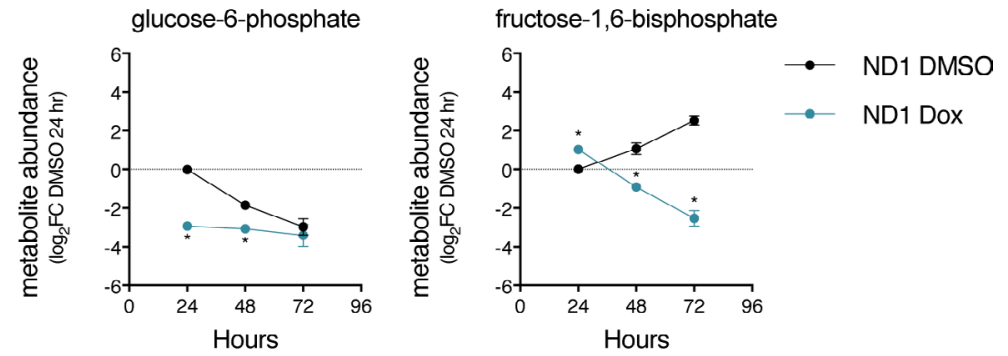

dihydroxy-acetone-phosphate
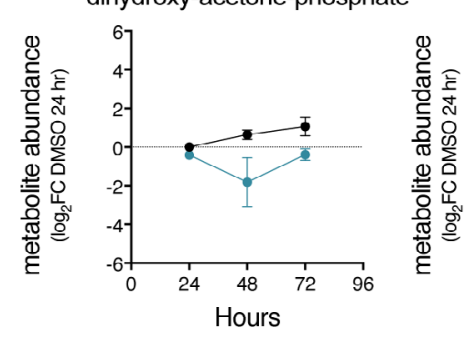

ribose-phosphate

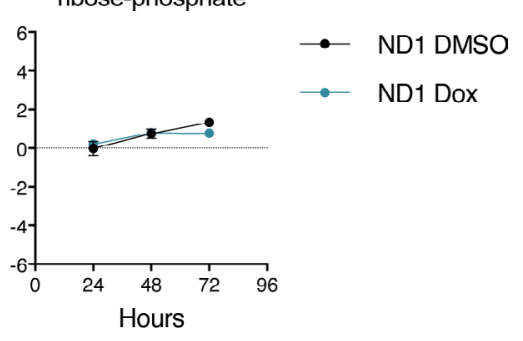

dTMP
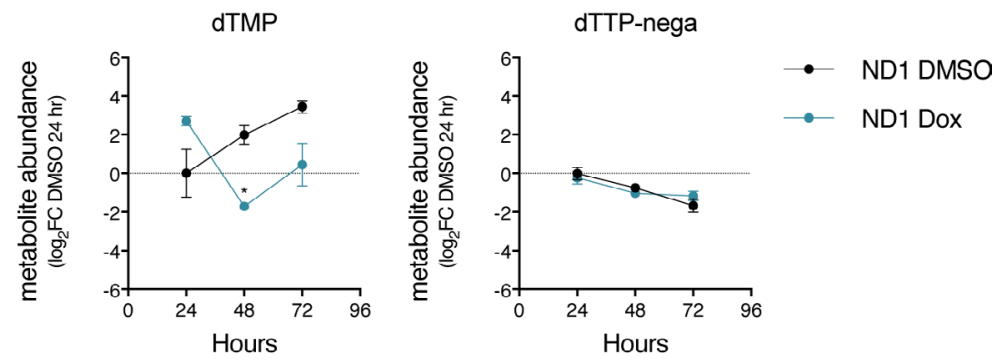
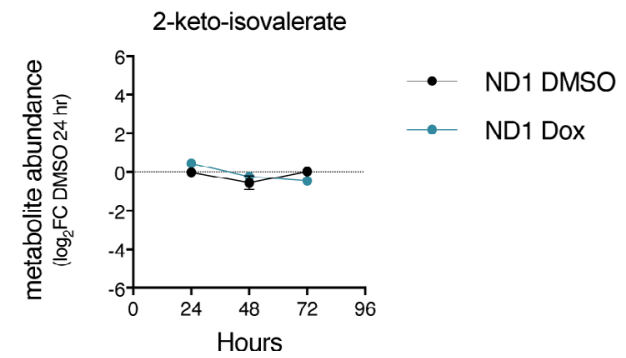

Extended Data Fig. 5 | Doxycycline suppresses inflammatory gene expression and metabolite levels in a time-dependent manner. a, Heatmap of metabolites in ND1 cybrid cells that significantly change with doxycycline (Dox) and 7066 compared to DMSO, 7004, 7013, and CMT-3 ( $n=3$ biologically independent samples, $p<0.05$, Student's t-test with Bonferroni's correction). b. Time-dependent gene expression of inflammatory markers in ND1 cybrid cells under galactose conditions ( $n=3$ biologically independent samples). c, Time-dependent metabolite changes in ND1 cybrid cells under galactose conditions ( $n=3$ biologically independent samples). Data are presented as mean values \pm s.e.m. error bars, Student's t-test with a two-stage linear step-up procedure of Benjamini, Krieger and Yekutieli, with $\mathrm{Q}=5 \%$, ${ }^{\star} q<0.05$. 

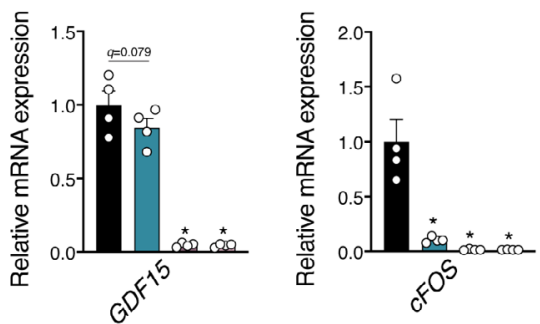

c.

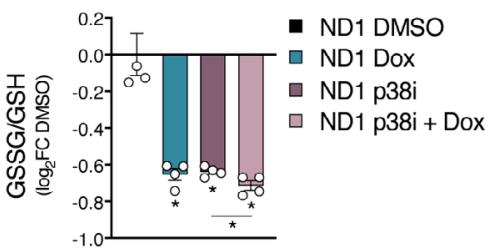

- ND1 DMSO

- ND1 Dox

- ND1 p38i

口 ND1 p38i + Dox b.

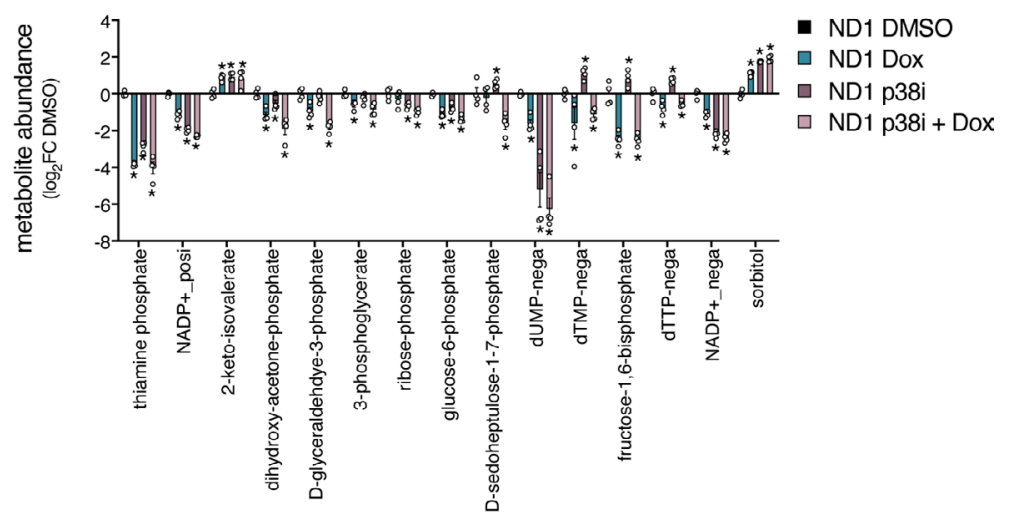

Extended Data Fig. 6 | p38 inhibition partially mimics the doxycycline anti-inflammatory metabolomic signature. a, Gene expression of inflammatory markers in ND1 cybrid cells treated with doxycycline (Dox) or p38i SB203580 after 48 hours galactose conditions ( $n=4$ biologically independent samples). b. Metabolite changes in doxycycline signature in ND1 cybrid cells treated with doxycycline or SB203580 after 48 hours galactose conditions ( $n=4$ biologically independent samples). c-d, Quantitation of GSSG/GSH and NADP+/NADPH ratio in ND1 cybrid cells with doxycycline or SB203580 treatment after 48 hours galactose conditions ( $n=4$ biologically independent samples). Data are presented as mean values \pm s.e.m. error bars, Student's t-test with a two-stage linear step-up procedure of Benjamini, Krieger and Yekutieli, with $Q=5 \%,{ }^{\star} q<0.05$. 
a.

Brain

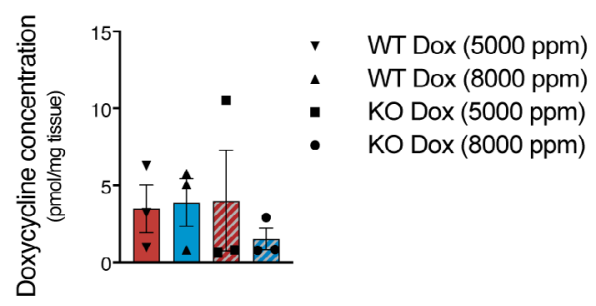

c.

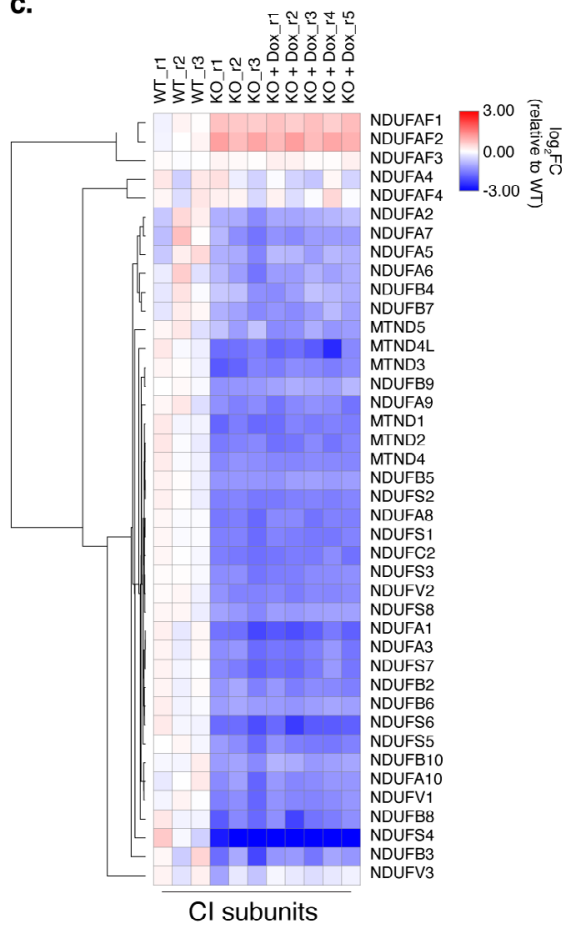

b.

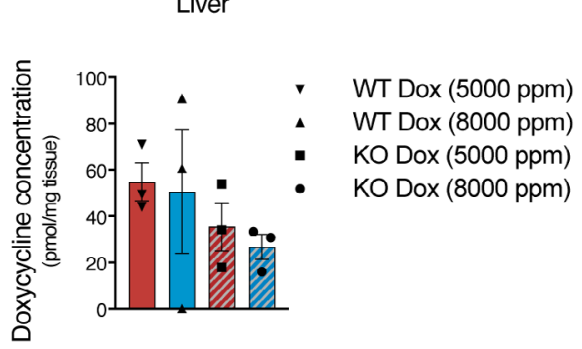

d.

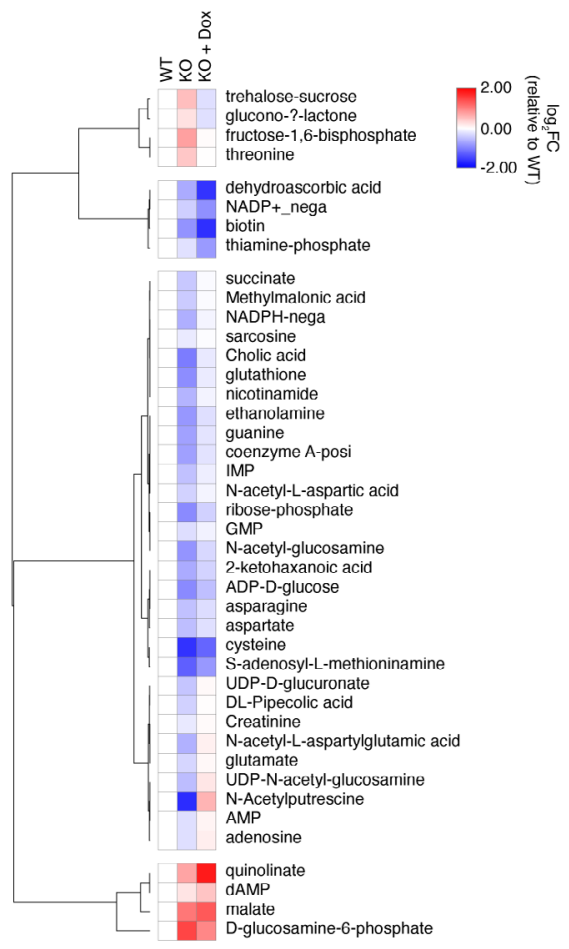

e.

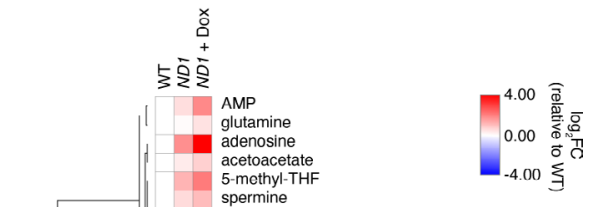

5-methyl-THF
spermine

3-phospho-serin

Pyrophosphate Pyrophosphate
deoxyinosine myo-inositol

isocitrate

Citraconic acid/taconic acid itaconic acid

L-arginino-succinate

dGDP-nega

ADP-nega

leucine-isoleucine 2-dehydro-D-gluconate Phenylpropioic acid acetyl-COA-DOSi
a-ketoglutarate a-ketoglu
citrate

2-Aminooctanoic acid Phosphorylcholine methionine 2-hydroxygluterate citrate-isocitrate
hexose-phosphate hexose-phosphate
glucose-1-phosphate Phenyllactic acid Creatinine 1-Methyl-Histidine histidine UDP-D-glucuronate adenine Methylcysteine
tyrosine tyrosine cystathionine
UDP-nega S-adenosyl-L-methionine taurine UDP-D-glucose UTP-nega
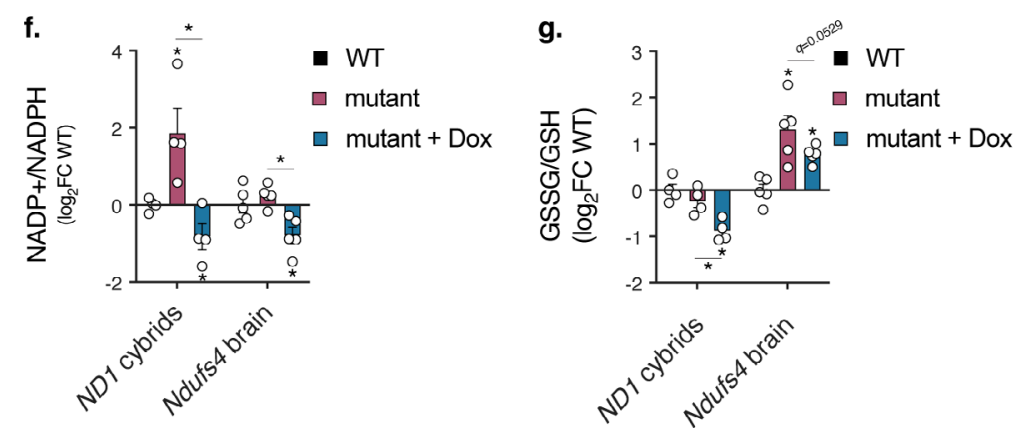
D-erythrose-4-phosphate shikimate cotinam

2,3-Diphosphoglyceric acid NADP+_nega adenosine 5-phosphosulfate -sedoheptulose-1-7-phosphate NADP+_posi phosphoenolpyruvate ephospho-CoA-nega SBP dUMP-nega D-glyceraldehdye-3-phosphate dihydroxy-acetone-phosphat
fructose-1, 6 -bisphosphate

Extended Data Fig. 7 | Doxycycline promotes metabolite redox homeostasis independent of complex I protein levels. a, Quantitation of doxycycline (Dox) in brains of wild-type and Ndufs $4^{-/-}$(KO) animals fed 5000 or $8000 \mathrm{ppm}$ doxycycline diets ( $\mathrm{n}=3$ mice per treatment group). b, Quantitation of doxycycline in livers of wild-type and $\mathrm{Ndufs}^{-{ }^{--}}(\mathrm{KO})$ animals fed 5000 or $8000 \mathrm{ppm}$ doxycycline diets $(\mathrm{n}=3$ mice per treatment group). $\mathbf{c}$, Heatmap of mitochondrial complex I subunits expressed in the mouse brains quantified through proteomics analysis $(n=3 W T, n=3 K O$, and $n=5 K O$ Dox mice). d, Heatmap of metabolites altered in Ndufs $4^{-/-}(\mathrm{KO})$ brains $(p<0.15$, Student's t-test, two-sided, unpaired) that are modulated by doxycycline ( $p<0.15$, Student's t-test, two-sided, unpaired) ( $n=5$ mice). e, Heatmap of metabolites altered in ND1 cybrid cells ( $p<0.05$, Student's t-test, two-sided, unpaired) that significantly change with doxycycline ( $p<0.05$, Student's t-test, two-sided, unpaired) ( $n=4$ biologically independent samples). $\mathrm{f}-\mathrm{g}$, Quantitation of $\mathrm{NADP}^{+} / \mathrm{NADPH}$ and GSSG/GSH ratios in ND1 cybrid cells or Ndufs $4^{--}(\mathrm{KO})$ brains with doxycycline treatment (cybrid cells, $\mathrm{n}=4$ biologically independent samples; mice, $n=5$ ). Data are presented as mean values \pm s.e.m. error bars, Student's t-test with a two-stage linear step-up procedure of Benjamini, Krieger and Yekutieli, with $\mathrm{Q}=5 \%,{ }^{\star} q<0.05$. 


\section{Reporting Summary}

Nature Research wishes to improve the reproducibility of the work that we publish. This form provides structure for consistency and transparency in reporting. For further information on Nature Research policies, see our Editorial Policies and the Editorial Policy Checklist.

\section{Statistics}

For all statistical analyses, confirm that the following items are present in the figure legend, table legend, main text, or Methods section.

n/a Confirmed

\ The exact sample size $(n)$ for each experimental group/condition, given as a discrete number and unit of measurement

$\square$ A statement on whether measurements were taken from distinct samples or whether the same sample was measured repeatedly

$\square$ The statistical test(s) used AND whether they are one- or two-sided

$\square$ Only common tests should be described solely by name; describe more complex techniques in the Methods section.

$\square$ A description of all covariates tested

$\square$ \A description of any assumptions or corrections, such as tests of normality and adjustment for multiple comparisons

$\square$ A full description of the statistical parameters including central tendency (e.g. means) or other basic estimates (e.g. regression coefficient)

$\triangle$ AND variation (e.g. standard deviation) or associated estimates of uncertainty (e.g. confidence intervals)

For null hypothesis testing, the test statistic (e.g. $F, t, r$ ) with confidence intervals, effect sizes, degrees of freedom and $P$ value noted

Give $P$ values as exact values whenever suitable.

$\bigotimes$ For Bayesian analysis, information on the choice of priors and Markov chain Monte Carlo settings

$\bigotimes$ For hierarchical and complex designs, identification of the appropriate level for tests and full reporting of outcomes

$\bigotimes$ Estimates of effect sizes (e.g. Cohen's $d$, Pearson's $r$ ), indicating how they were calculated

Our web collection on statistics for biologists contains articles on many of the points above.

\section{Software and code}

Policy information about availability of computer code

Data collection Microsoft Excel for Mac Version 16.43, GraphPad Prism 8 for macOS (Version 8.4.0)

Data analysis Microsoft Excel for Mac Version 16.43, GraphPad Prism 8 for macOS (Version 8.4.4), ImageJ Version 2.0.0-rc-44/1.50e, MetaboAnalyst v4.0.2, Morpheus, DAVID Bioinformatics Resources 6.8, ChimeraX Version 1.0, ChemDraw 19.1.1.32

For manuscripts utilizing custom algorithms or software that are central to the research but not yet described in published literature, software must be made available to editors and reviewers. We strongly encourage code deposition in a community repository (e.g. GitHub). See the Nature Research guidelines for submitting code \& software for further information.

\section{Data}

Policy information about availability of data

All manuscripts must include a data availability statement. This statement should provide the following information, where applicable:

- Accession codes, unique identifiers, or web links for publicly available datasets

- A list of figures that have associated raw data

- A description of any restrictions on data availability 


\section{Field-specific reporting}

Please select the one below that is the best fit for your research. If you are not sure, read the appropriate sections before making your selection.

$\bigotimes$ Life sciences $\quad \square$ Behavioural \& social sciences $\quad \square$ Ecological, evolutionary \& environmental sciences

For a reference copy of the document with all sections, see nature.com/documents/nr-reporting-summary-flat.pdf

\section{Life sciences study design}

All studies must disclose on these points even when the disclosure is negative.

Sample size A sample size of two replicates per condition was selected for initial experiments. Additional experiments were performed and replicates were often pooled. For the majority of our techniques, biologically meaningful differences are detected with 3-8 replicates. For certain studies an $\mathrm{n}=2$ biologically independent samples were used; although less robust biologically, these generally reflect experiments requiring greater resources. For mouse studies, sample sizes were based on the animal numbers used in studies reporting similar outcomes including Jain et al. Science, 2016 and Johnson et al., Science 2013. A sample size calculation was not used initially for the study as we did not have an expectation of the lifespan difference until the first few mice had met euthanasia criteria, once mouse numbers were similar to the aforementioned studies, we performed log-rank test analysis using GraphPad Prism software and found our lifespan difference to be statistically significant.

Data exclusions No data exclusions

Replication Attempts were made to reproduce all cell survival experiments at least twice and ideally three times. Results were reproducible between experiments.

Randomization Mice were randomly assigned to treatments. In general, litter mates were separated into different treatments and males and females were distributed evenly amongst treatments.

Blinding $\quad$ Primary investigator of mouse studies (E.A.P) was not blinded, however pathologist was blinded to the identity of histology samples when performing analysis. Blinding was not performed as the animal facility requires investigators to care and administer feed to his/her own mice. As E.A.P. performed all mouse studies, she needed to administer special diet and keep records of which mice and which cages were given each kind of diet. The diets were also color coded with food dye to prevent any mistakes which made the treatment groups clearly marked.

Regarding omics experiments such as proteomics and metabolomics, the collaborators performing these experiments were blinded as to the conditions of each sample. Therefore the initial analysis performed by these collaborators was blinded regarding treatment groups and protein/metabolites of interest.

For MS of doxcycyline concentration in brains and livers, samples were submitted using a numerical code only known to E.A.P. and C.F.B., therefore the collaborator was blinded as to the treatment group of each sample.

\section{Reporting for specific materials, systems and methods}

We require information from authors about some types of materials, experimental systems and methods used in many studies. Here, indicate whether each material, system or method listed is relevant to your study. If you are not sure if a list item applies to your research, read the appropriate section before selecting a response.

\begin{tabular}{l|l} 
Materials \& experimental systems \\
\hline $\mathrm{n} / \mathrm{a}$ & Involved in the study \\
\hline & $\bigotimes$ Antibodies \\
$\square$ & $\square$ Eukaryotic cell lines \\
$\square$ & $\square$ Animaeontology and archaeology \\
$\square$ & $\square$ Clinical data \\
$\square$ Dual use research of concern
\end{tabular}

\begin{tabular}{|c|c|}
\hline $\mathrm{n} / \mathrm{a}$ & Involved in the study \\
\hline X & ChIP-seq \\
\hline Х & Flow cytometry \\
\hline$\bigotimes$ & MRI-based neuroimaging \\
\hline
\end{tabular}

Antibodies

Antibodies used anti-SDHA (Abcam, ab14715), anti-MTCO1 (Abcam, ab14705), anti-NDUFA9 (Abcam, ab14713), anti-UQCRC2 (Abcam, ab14745), antiATF4 (Cell Signaling, 11815), anti- $\beta$-actin (Cell Signaling, 4967), p-elF2? (Ser51) (Cell Signaling, 3398), total elF2? (Cell Signaling, 5324), anti-CHOP (Cell Signaling, 2895), anti- $\beta$-Tubulin (Cell Signaling, 2146), anti-MRPL4 (Proteintech, 27484-1-AP), anti-GFM2 (Proteintech, 16941-1-AP), anti-UQCRB (1:1000) (Proteintech, 10756-1-AP)Alexa 488 (Thermo Fisher Scientific, B40953), IBA-1 (Wako, 019-19741, polyclonal) and anti-PAR1 (Abcam, ab32611)

Validation
For all primary antibodies, we initially validated by looking at the predicted size based on the manufacturers website as well and in previous publications. Use of CRISPR deletions and siRNA allowed for further validation of some antibodies (MRPL4, GFM2, ATF4, 
PAR-1).

For iba-1 the Specialized Histopathology Core at the Brigham and Women's Hospital previously validated this antibody in mouse brain sections. Additionally, this antibody was used in Jain et al., Science, 2013 using the same Ndufs4-/- mouse strain as used in our study.

\section{Eukaryotic cell lines}

Policy information about cell lines

Cell line source(s)

MELAS, ND1, LHON(ND6) cybrid cells are human patient fibroblast fused to U2OS cells depleted of mtDNA. Rieske KO fibroblasts were isolated from Rieske KO mouse. MELAS cybrid cells and Rieske KO fibroblasts were obtained from Carlos Moraes, University of Miami, Miami, FL. ND1 and ND6 cybrid cells as well as U2OS controls were obtained from Rutger Vogel and Jan Smeitink, Radbound University Medical Centre, Netherlands. HEK293T cells were also used for virus production (source unknown).

Authentication

Cell lines were not authenticated. MELAS and ND1 Cell lines were verified by RFLP mapping.

Mycoplasma contamination

Cell lines were tested for mycoplasma and all cell lines tested negative using Lonzana Mycoalert Kit.

Commonly misidentified lines (See ICLAC register)

\section{None}

\section{Animals and other organisms}

Policy information about studies involving animals; ARRIVE guidelines recommended for reporting animal research

Laboratory animals

C57BL/6J both males and females used. Ndufs4+/- strain purchased from Jackson Laboratory (B6.129S4-Ndufs4tm1.1Rpa/J, Stock No. 027058)

\section{Wild animals \\ None \\ Field-collected samples \\ None}

Ethics oversight

IUACUC of the Beth Israel Deaconess Medial Center

Note that full information on the approval of the study protocol must also be provided in the manuscript. 